\title{
Revisão de Pseudoparlatoria (Hemiptera, Diaspididae)
}

\author{
Vera Regina dos S. Wolff
}

Fundação Estadual de Pesquisa Agropecuária (FEPAGRO), Rua Gonçalves Dias, 570, 90130-060 Porto Alegre, RS. (verawolff@fepagro.rs.gov.br)

\begin{abstract}
Review of Pseudoparlatoria (Hemiptera, Diaspididae). The armored scale insects of genus Pseudoparlatoria Cockerell, 1892 were revised through the exam of the type series, species obtained in the type-localities and available material in scientific collections. Pseudoparlatoria argentata Hempel, 1912; P. browni McKenzie, 1963; P. campinensis Lepage \& Giannotti, 1946; P. carolilehmanni Balachowsky, 1959; P. caucae Balachowsky, 1959; P. circularis Lepage, 1942; P. constricta Fonseca, 1975; P. elongata Ferris, 1941; P. fusca Ferris, 1941; P. fusiformis Fonseca, 1969; P. lentigo Ferris, 1942; P. maculata Ferris, 1942; P. noacki Cockerell, 1898; P. occultata (Hempel, 1937); P. ostreata Cockerell, 1892; P. parlatorioides (Comstock, 1883); P. perparvula Ferris, 1942; P. pisai (Hempel, 1904); P. punctata Ferris, 1942; P. rossetae Fonseca, 1969; P. serrulata Townsend \& Cockerell, 1898; P. subcircularis Balachowsky, 1959; P. tillandsiae Tippins, 1970; P. trimaculata Lepage \& Giannotti, 1946; P. turgida Ferris, 1941 were redescribed. Pseudoparlatoria mammata (Ferris, 1941) and P. sculpta (Ferris, 1941) are new combinations. An identification key to species is provided.
\end{abstract}

KEYWORDS. Taxonomic revision, armored scale insect, diaspidid, Neotropical.

RESUMO. Revisou-se a taxonomia das espécies incluídas em Pseudoparlatoria Cockerell, 1892, através do exame das séries tipo, exemplares obtidos nas localidades-tipo e material disponível em coleções científicas. Foram redescritas: P. argentata Hempel, $1912 ;$ P. browni McKenzie, 1963; P. campinensis Lepage \& Giannotti, 1946; P. carolilehmanni Balachowsky, 1959; P. caucae Balachowsky, 1959; P. circularis Lepage, 1942; P. constricta Fonseca, 1975; P. elongata Ferris, 1941; P. fusca Ferris, 1941; P. fusiformis Fonseca, 1969; P. lentigo Ferris, 1942; P. maculata Ferris, 1942; P. noacki Cockerell, 1898; P. occultata (Hempel, 1937); P. ostreata Cockerell, 1892; P. parlatorioides (Comstock, 1883); P. perparvula Ferris, 1942; P. pisai (Hempel, 1904); P. punctata Ferris, 1942; P. rossetae Fonseca, 1969; P. serrulata Townsend \& Cockerell, 1898; P. subcircularis Balachowsky, 1959; P. tillandsiae Tippins, 1970; P. trimaculata Lepage \& Giannotti, 1946; P. turgida Ferris, 1941. Duas novas combinações são estabelecidas, P. mammata (Ferris, 1941); P. sculpta (Ferris, 1941). Uma chave para identificação das espécies é apresentada.

PALAVRAS-CHAVE. Revisão taxonômica, cochonilhas-com-escudo, diaspidídeos, Neotropical.

Os diaspidídeos, insetos conhecidos como "cochonilhas-com-escudo", são parasitos de diversas plantas e capazes de provocarem perdas significativas na produção agrícola.

A maioria das espécies de Pseudoparlatoria Cockerell, 1892 (Hemiptera, Coccoidea, Diaspididae) é neotropical, algumas espécies ocorrem no sul da região neártica e poucas são cosmopolitas (BorCHSENIUS, 1966; FonseCA, 1969, 1975; TIPPINS, 1970).

Originalmente foram descritas 32 espécies (COMSTOCK, 1883; COCKERELl, 1892, 1898a,b,c; TOWNSEND \& CoCKERell, 1898; HeMpel, 1904, 1912, 1937; Lindinger, 1909, 1911; FERRIS, 1941a,b, 1942; LePAGE, 1942; LEPAGE \& GiannotTi, 1943, 1946; Mamet, 1953; Balachowsky, 1959; McKenZIE, 1963; FonseCA, 1969, 1975; TIPPINS, 1970).

A redescrição de Pseudoparlatoria e a descrição de dez espécies novas é encontrada no trabalho de WoLfF (2001).

Considerando a necessidade de estudos taxonômicos dos diaspidídeos neotropicais, este trabalho redescreve as espécies de Pseudoparlatoria e fornece informações sobre a localização do material-tipo, distribuição geográfica e plantas hospedeiras.

\section{MATERIAL E MÉTODOS}

Foram examinados espécimes-tipo e outros exemplares das seguintes Instituições: Fundación y
Instituto Miguel Lillo, Universidad Nacional de Tucumán, San Miguel de Tucumán, Argentina (IMLA); Instituto Biológico, Secretaria da Agricultura, São Paulo, Brasil (IBSP); Museu de Ciências e Tecnologia, Pontifícia Universidade Católica do Rio Grande do Sul, Porto Alegre, Brasil (MCTP); Museu de Entomologia Pe. Jesus Santiago Moure, Departamento de Zoologia da Universidade Federal do Paraná, Curitiba, Brasil (DZUP); Museu de Zoologia, Universidade de São Paulo, São Paulo, Brasil (MZSP); Museu Ramiro Gomes Costa, Fundação de Pesquisa Agropecuária do Rio Grande do Sul, Porto Alegre, Brasil (MRGC); Muséum National D'Histoire Naturelle, Paris, França (MNHN); National Museum of Natural History, Smithsonian Institution, Washington D.C., USA (USNM); The Bohart Museum of Entomology, University of California, Davis, USA (UCDC); The Natural History Museum, London, Inglaterra (BMNH); Virginia Museum of Natural History at Virginia Tech, Virginia Polytechnic Institute and State University, Blacksburg, USA (VPIC); Zoologisches Institut und Zoologisches Museum, Abteilung Entomologie, Universität Hamburg, Hamburg, Alemanha (ZMUH).

Foram preparadas lâminas permanentes do material proveniente de coletas eventuais, utilizando-se solução de $\mathrm{NaOH}$, a $10 \%$, desidratação com série alcoólica e montagem em Bálsamo do Canadá, que foram depositadas no MRGC.

$\mathrm{Na}$ lista de hospedeiros e distribuição geográfica, 
além dos dados das etiquetas, são acrescentadas informações da bibliografia.

\section{RESULTADOS E DISCUSSÃO}

Foram estudadas 35 espécies de Pseudoparlatoria, das quais 25 foram redescritas e duas foram transferidas de Malleolaspis Ferris, 1941, resultando em novas combinações. As espécies $P$. chilina Lindinger, 1909, $P$. cristata Lindinger, 1911, P. gomescostai Lepage \& Giannotti, 1946, P. memorabilis Ferris, 1941, P. multipunctata Lepage \& Giannotti, 1946, P. petasata Ferris, 1942 e $P$. triangularis Mamet, 1954, não foram incluídas porque não apresentam os caracteres diagnósticos do gênero.

$\mathrm{Na}$ chave dicotômica incluem-se as 27 espécies redescritas e as dez espécies de Pseudoparlatoria descritas em WoLfF (2001)

Chave para identificação das espécies de Pseudoparlatoria, baseada nos caracteres de fêmeas adultas.

1. Lóbulos medianos com margens lisas, arredondadas ou triangulares

1'. Lóbulos medianos com reentrâncias nas margens

2. Sem macrocondutos marginais entre os lóbulos medianos

2'. Com macrocondutos marginais entre os lóbulos medianos

3. Grupos laterais de glândulas circungenitais com 16 ou mais glândulas ........ P. pisai (Hempel, 1904)

3'. Mesmos grupos com menos de 16 glândulas ...... P. campinensis Lepage \& Giannotti, 1946

4. Até sete macrocondutos marginais ................... 5

4'. Mais de sete macrocondutos marginais ............ 7

5. Constrição no ápice do protórax P. constricta Fonseca, 1975

5'. Sem constrição no ápice do protórax ................... 6

6. Corpo esclerotizado além do pigídio P. pontiaguda Wolff, 2001

6'. Corpo membranoso, apenas pigídio esclerotizado P. argentata Hempel, 1912

7. Sem lobos abdominais pré-pigidiais

7'. Com lobos abdominais pré-pigidiais ................ 11

8. Macrocondutos até os primeiros segmentos abdominais

P. carolilehmanni Balachowsky, 1959

8'. Macrocondutos restritos ao pigídio ................... 9

9. Segundo par de lóbulos pigidiais reduzidos ........ P. subcircularis Balachowsky, 1959

9'. Segundo par de lóbulos pigidiais desenvolvidos

10. Cerca de nove pares de macrocondutos submarginais no pigídio ........... P. caucae Balachowsky, 1959

10'. Cerca de dezoito pares de macrocondutos submarginais no pigídio

P. clapsae Wolff, 2001

11. Macrocondutos submarginais até os primeiros segmentos abdominais
11'. Macrocondutos submarginais restritos ao pigídio

12. Terceiro par de lóbulos pigidiais inconspícuo, escudo com três manchas escuras na segunda exúvia P. trimaculata Lepage \& Giannotti, 1946

12'. Terceiro par de lóbulos pequenos, escudo sem manchas ......................... P. fusca Ferrris, 1941

13. Apenas um lóbulo abdominal pré-pigidial desenvolvido .............. P. lentigo Ferrris, 1942

13'. Dois lóbulos abdominais pré-pigidiais desenvolvidos

14. Manchas "s" características no pigídio

14'. Sem manchas "s" no pigídio $P$. anthurium Wolff, 2001

P. maculata Ferris, 1942

15. Lóbulos medianos com mais de uma reentrância de cada lado das margens ................................ 16

15'. Lóbulos medianos com uma reentrância de cada lado das margens

17

16. Corpo alongado, com vários lobos abdominais prépigidiais ............... P. tillandsiae Tippins, 1970

16'. Corpo oval, sem lobos abdominais pré-pigidiais P. juncea Wolff, 2001

17. Protórax semicircular com constrição no metatórax

17'. Corpo não com esta forma ............................... 20

18. Sem macroconduto marginal entre os lóbulos medianos ............. P. fusiformis Fonseca, 1969

18'. Com macroconduto marginal entre os lóbulos medianos

19. Metatórax e primeiro segmento abdominal com lobos pontiagudos ........... P. mammata (Ferris, 1941)

19'. Metatórax e primeiro segmento abdominal sem lobos pontiagudos .............. P. sculpta (Ferris, 1941)

20. Menos de seis pares de macrocondutos marginais

20 '. Seis ou mais pares de macrocondutos marginais ..

22

21. Macrocondutos submarginais em grande número, não restritos ao pigídio

P. circularis Lepage, 1942

21'. Macrocondutos submarginais em pequeno número, restritos ao pigídio ......... P. suelda Wolff, 2001

22. Glândulas dorsais curtas em série, nas margens do cefalotórax

22'. Sem este tipo de glândulas dorsais no cefalotórax

23. Segundo par de lóbulos.................................... 24 P. punctata Ferris, 1942

23'. Segundo par de lóbulos reduzidos P. rossettae Fonseca, 1969

24. Com macroconduto marginal entre os lóbulos medianos ................................................. 25

24'. Sem macroconduto marginal entre os lóbulos medianos

25. Lobos abdominais pré-pigidiais bem desenvolvidos P. noacki Cockerell, 1898

25'. Sem lobos abdominais pré-pigidiais

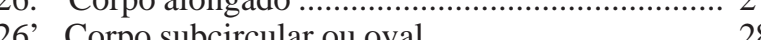

27. Corpo inteiramente esclerotizado, $2^{\circ}$ par de lóbulos reduzidos P. turgida Ferris, 1941 
27'. Corpo membranoso, $2^{\circ}$ par de lóbulos pigidiais desenvolvidos ........... P. elongata Ferris, 1941

28. Lobos abdominais pré-pigidiais bem desenvolvidos 29

28'. Sem lobos abdominais pré-pigidiais ou pouco desenvolvidos 30

29. Dois a três lobos abdominais pré-pigidiais P. lobata Wolff, 2001

29'. Um lobo abdominal pré-pigidial P. podocarpus Wolff, 2001

30. Macrocondutos submarginais restritos ao pigídio

30'. Macrocondutos submarginais desde os primeiros segmentos abdominais 34

31. Ânus afastado da margem pigidial P. aeranthos Wolff, 2001

31'. Ânus mais próximo da margem pigidial

32. Com lóbulos abdominais pré-pigidiais P. perparvula Ferris, 1942

32'. Sem lóbulos abdominais pré-pigidiais ... 33

33. Terceiro par de lóbulos pigidiais reduzidos

33'. Terceiro par de lóbulos bilobados P. chiapensis Wolff, 2001 P. parlatorioides (Comstock, 1883)

34. Manchas "s" na região mediana do pigídio P. browni McKenzie, 1963

34'. Sem as manchas 35

35. Ânus afastado da margem pigidial P. occultata (Hempel, 1937)

35'. Ânus próximo à margem pigidial 36

36. Com lóbulos abdominais pré-pigidiais P. ostreata Cockerell, 1898

36'. Sem lóbulos abdominais pré-pigidiais P. serrulata Townsend \& Cockerell, 1898

\section{Pseudoparlatoria argentata Hempel, 1912}

Pseudoparlatoria argentata Hempel, 1912:51, 63-65; VernalHa, 1953:192 (cat.), 1957:24, 26 (combinação revalidada, fig.); BorChSENIUS, 1966:162 (cat.).

Parlatoreopsis argentata; Costa Lima, 1936:192 (cat.); LePAGE, 1938:413 (cat.); Lizer y Trelles 1942:234; Costa \& Redaelli, 1949:66; SiLva et al., 1968:177 (cat.).

Redescrição. Escudo do macho alongado, em média, $0,84 \mathrm{~mm}$ de comprimento e $0,48 \mathrm{~mm}$ de largura; exúvia apical, amarela. Escudo da fêmea adulta circular a subcircular, em média 1,25 mm de comprimento e $1,16 \mathrm{~mm}$ de largura, rugoso, convexo, marrom-escuro a preto com a margem achatada, mais clara e transparente; exúvias próximas da margem do escudo, a primeira pequena e amarelo-clara, a segunda grande, transparente na margem e o resto com uma mancha triangular, preta.

Fêmea adulta subcircular, membranosa, apenas o pigídio esclerotizado, em média $0,59 \mathrm{~mm}$ de comprimento, $0,57 \mathrm{~mm}$ de largura; tubérculo antenal com uma seta longa, espiráculos anteriores e posteriores sem glândulas, três grandes lobos abdominais pré-pigidiais. Pigídio com três pares de lóbulos muito curtos: L1 largos, com margens lisas e ápice arredondado; L2 e L3 bilobados. Entre os L1 há um par de espinhos glandulares unidos na base e com pontas simples, em forma de "y"; entre L1 e L2 e entre L2 e L3 há um espinho glandular, de cada lado, com ponta simples, todos mais longos do que os lóbulos; demais espinhos glandulares reduzidos. Margem anterior aos lóbulos pigidiais espessa e finamente dentada. Um macroconduto marginal entre os L1; outro entre L1 e L2 e dois entre L2 e L3, de cada lado das margens. Macrocondutos submarginais bem menores que os marginais, em grande número, do VIII até os primeiros segmentos abdominais. Ânus, em média, a 0,05 mm da margem pigidial. Glândulas circungenitais em cinco grupos, raramente em quatro: 0-4 mediano, 12-19 ânterolaterais, 14-25 póstero-laterais. Grande quantidade de microcondutos nos lobos abdominais pré-pigidiais e espalhados pelo pigídio.

Material-tipo. Não localizado. Não há indicação na descrição original do depósito do material-tipo.

\section{Localidade-tipo. Brasil, São Paulo: Campinas.}

Material examinado. BRASIL, Mato Grosso: Vila Bela de Santíssima Trindade, 5‡, 1 lâmina, 1923, sem coletor, ex. "planta silvestre" (IBSP); Bahia: Barreiro, 13q, 3 lâminas, XII.1976, Bondar col. (MZSP 181); Minas Gerais: Caraça, 11థ, 2 lâminas, VII.1973, J. P. da Fonseca col. (MZSP 354); Rio de Janeiro: 4.IX.1934, H. Compere col., ex. "planta ornamental" (UCDC); São Paulo: 6‡, 1 lâmina, IV.1938, H. S. Lepage col., ex. Aglaia sp. (IMLA); Santos, 26‡, 4 lâminas, 18.VII.1934, H. S. Lepage col., ex. "murta" (MZSP 395); escudos de ơ e 9 em material herborizado, 18.VII.1934, H. S. Lepage col., ex. "murta" (IBSP 395); 21\&, 3 lâminas, IV.1965, J. P. da Fonseca col., ex. Aglaia sp. (MZSP 230); \&, XI.1972, sem coletor, ex. "erva-mate" (MZSP 576); 8f, 1 lâmina, sem data, sem coletor (IBSP); Rio Grande do Sul: 3̊, 1 lâmina, VI.1932, M.V. Parseval col., ex. Ilex sp. (MRGC 0001); 5૬, 1 lâmina, VI.1932, M.V. Parseval col., ex. Ilex sp. (MRGC 0002); ARGENTINA, Misiones: Puerto Libertad, 4\&, 2 lâminas, 13.I.1945, Hayward col. (IMLA 3561); Corrientes: Corrientes, 20\&, 1 lâmina, VII.1938, Bousquet col., ex. "Aguay" (INTA Castelar)

Distribuição geográfica. Brasil, desde o Mato Grosso até o Rio Grande do Sul; Nordeste da Argentina, nas províncias de Misiones e Corrientes.

Hospedeiros. Aquifoliaceae: Ilex paraguayensis, Ilex sp.; Lauraceae: Laurus nobilis; Loranthaceae: Loranthus sp. e Phoradendron sp.; Meliaceae: Aglaia sp.; Myrtaceae: Myrta sp.; Rutaceae: Citrus sp.; Sapotaceae: Chrysophyllum sp., Chysophyllum lucumifolium; Theaceae: Camelia sp.; planta silvestre.

Discussão. Semelhante a Pseudoparlatoria constricta Fonseca, 1975 por apresentar quantidade reduzida de macrocondutos marginais; macrocondutos submarginais bem menores que os marginais desde os primeiros segmentos abdominais; vários microcondutos nos lobos abdominais pré-pigidiais e espalhados pelo pigídio; difere por não apresentar constrição na margem apical do cefalotórax.

Costa Lima (1936) cita a espécie no gênero Parlatoreopsis Lindinger, 1912, seguido por LePAGE (1938) e Lizer y Trelles (1942). Vernalha (1957) revalida a combinação com Pseudoparlatoria.

\section{Pseudoparlatoria browni McKenzie, 1963}

Pseudoparlatoria browni McKenZIE, 1963:36-37 (fig.); BorChSEnIUS, 1966:162 (cat.); MiLLeR, 1996:78. 
Redescrição. Macho desconhecido. Escudo da fêmea adulta de forma irregular, achatado, muito membranoso e transparente (McKenZIE, 1963).

Fêmea adulta de forma oval, em média com $0,89 \mathrm{~mm}$ de comprimento, 0,59 $\mathrm{mm}$ de largura; tubérculo antenal com uma seta longa, espiráculos anteriores e posteriores sem glândulas, sem lobos abdominais pré-pigidiais. Pigídio com manchas "s" longitudinais, quase paralelas, na região mediana; três pares de lóbulos bem distintos: L1 bem desenvolvidos, com uma reentrância em cada lado das margens; L2 e L3 menores e bilobados. Entre os L1, encontra-se um par de espinhos glandulares em forma de " $y$ ", entre L1 e L2 e entre L2 e L3, espinhos glandulares de ápice simples, todos de comprimento maior que os lóbulos; antes de L3, os espinhos glandulares são inconspícuos. Margens anteriores aos lóbulos pigidiais com leve esclerotização. Não há macroconduto marginal entre os L1, há um entre L1 e L2, dois entre L2 e L3, três antes de L3, de cada lado das margens. Um macroconduto submarginal de cada lado, no VII segmento, quase do mesmo tamanho dos marginais; demais macrocondutos submarginais menores, até os primeiros segmentos abdominais. Ânus oval, em média a 0,04 mm da margem pigidial. Glândulas circungenitais em cinco grupos: 1-3 mediano, 8-20 ântero-laterais, 10-16 póstero-laterais. Pequena quantidade de microcondutos no pigídio.

Material-tipo. Holótipo não examinado. Parátipos: MÉXICO, Baja California Sur: La Paz, 3థ, 3 lâminas, 29.X.1958, S.W. Brown col., ex. "arbusto indeterminado" (UCDC). CHILE, Los Andes: Aconcagua, El Salto del Soldado, $\&$, 26.X.1959, C. Munez col., ex. Ephedra andina (USNM 590681).

Distribuição geográfica. México, Chile.

Hospedeiro. Ephedraceae: Ephedra andina ex C. A. Mey; arbusto indeterminado.

Discussão. Semelhante a Pseudoparlatoria occultata (Hempel, 1937) quanto à forma dos lóbulos pigidiais; tamanho e quantidade de macrocondutos marginais e submarginais; cinco grupos de glândulas circungenitais; difere por apresentar no pigídio manchas "s" longitudinais, quase paralelas, na região mediana.

Segundo McKenzie (1963), o comprimento e largura do corpo de fêmeas adultas são respectivamente: $1 \mathrm{~mm} \mathrm{e} 0,80 \mathrm{~mm}$, maiores do que as encontradas no material examinado; glândulas circungenitais em cinco grupos: grupo mediano=1-4; ântero-laterais $=17$; pósterolaterais $=15$, quantidades semelhantes às do material examinado.

\section{Pseudoparlatoria campinensis Lepage \& Giannotti, 1946}

Pseudoparlatoria campinensis LePage \& GiannotTi, 1946:42-44 (fig.); Vernalha, 1953:193 (cat.); Borchsenius, 1966:162 (cat.).

Redescrição. Escudo do macho alongado, em média $0,85 \mathrm{~mm}$ de comprimento e $0,5 \mathrm{~mm}$ de largura, branco leitoso, exúvia apical, amarela. Escudo da fêmea adulta circular, em média $0,9 \mathrm{~mm}$ de comprimento e $0,95 \mathrm{~mm}$ de largura, branco leitoso, exúvias excêntricas, amarelas.

Fêmea adulta circular até oval, em média, $0,56 \mathrm{~mm}$ de comprimento e $0,48 \mathrm{~mm}$ de largura, membranosa com exceção do pigídio, tubérculo antenal com uma seta longa, espiráculos anteriores e posteriores sem glândulas, sem lobos abdominais pré-pigidiais. Pigídio pequeno, com três pares de lóbulos: L1 arredondados; L2 bilobados, pouco desenvolvidos; L3 representados apenas por pequena ponta. Entre os L1, um par de espinhos glandulares em forma de "y"; entre L1 e L2 e entre L2 e L3, um espinho glandular com ápice simples, em cada lado das margens, mais longo que os lóbulos; antes de L3, espinhos glandulares inconspícuos. Margens anteriores a L3 simples. Sem macroconduto marginal entre os L1, um entre L1 e L2 e outro entre L2 e L3. Macrocondutos submarginais menores que os marginais restritos ao pigídio. Ânus, em média, a $0,02 \mathrm{~mm}$ da margem pigidial. Glândulas circungenitais em cinco grupos: 3-5 mediano, 5-8 ânterolaterais, 3-8 póstero-laterais. Grande quantidade de microcondutos por todo o pigídio e primeiros segmentos abdominais.

Material-tipo. Aqui designado: lectótipo ఢ. BRASIL, São Paulo: Campinas, 29.III.1945, H.S. Lepage col., ex. "planta indeterminada" (IBSP); paralectótipos: 11q, 3 lâminas, mesmos dados do lectótipo (1 lâmina retida MRGC 339); um tubo de vidro com escudos em material herborizado (IBSP).

Material examinado. BRASIL, São Paulo: Campinas, 24q, 6 lâminas, sem data, sem coletor, (MZSP 594); tubo de vidro com escudos em material heborizado (MZSP 594).

Distribuição geográfica. Brasil.

Discussão. Segundo LePAGE \& GiannotTi (1946), o comprimento do corpo da fêmea adulta é $0,75 \mathrm{~mm}$, maior do que a média das fêmeas examinadas.

\section{Pseudoparlatoria carolilehmanni Balachowsky, 1959}

Pseudoparlatoria carolilehmanni BaLACHOWSKY, 1959:350-351 (fig.); Borchsenius, 1966:162 (cat.); Miller, 1996:78.

Redescrição. Macho desconhecido. Escudo da fêmea circular, diâmetro entre 0,9-1 mm, achatado, marromclaro, com bordos mais claros; exúvia excêntrica, com um marcado estreitamento anterior (BALACHOWSKY, 1959).

Fêmea adulta subcircular, em média $0,55 \mathrm{~mm}$ de comprimento e $0,5 \mathrm{~mm}$ de largura, membranosa, tubérculo antenal com uma seta; espiráculos anteriores e posteriores sem glândulas, sem lobos abdominais pré-pigidiais. Pigídio com três pares de lóbulos: L1 arredondados, tão largos quanto longos; L2 pequenos, bilobados; L3 muito reduzidos. Espinhos glandulares mais longos que os lóbulos, um par em forma de "y" entre os L1; entre L1 e L2 e entre L2 e L3 um espinho glandular, em cada lado da margem, com pontas simples; antes de L3 os espinhos glandulares são muito curtos sobre os segmentos V, IV e III. Um macroconduto marginal entre os L1, um entre L1 e L2, dois entre L2 e L3, três antes de L3, de cada lado. Macrocondutos submarginais em grande número, sendo que os que se encontram nos segmentos VI e VII são quase do mesmo tamanho dos marginais, entre os segmentos I e V, são menores. Ânus, em média, a 0,04 mm da margem pigidial. Glândulas circungenitais em quatro grupos: 8-10 ântero-laterais, 5-6 póstero-laterais. Microcondutos em pequeno número, restritos ao pigídio. 
Material-tipo. Aqui designado: lectótipo §. COLÔMBIA, Cauca: Popayán, 16.II.1957, A. Balachowsky col., ex. Inga sp. (MNHN 2601); paralectótipos: 7‡, 6 lâminas, mesmos dados do lectótipo (MNHN 2601).

Material examinado. BRASIL, 86థ, 7 lâminas, sem data, sem coletor, ex. "planta silvestre" (MZSP) (1 lâmina ret. MRGC $342)$.

Distribuição geográfica. Colômbia, Brasil. silvestre.

Hospedeiro. Leguminosae: Inga sp.; planta

Discussão. Semelhante a Pseudoparlatoria caucae Balachowsky, 1959 pela forma dos lóbulos pigidiais e presença de macrocondutos entre os lóbulos medianos; difere daquela por apresentar maior quantidade de macrocondutos submarginais.

\section{Pseudoparlatoria caucae Balachowsky, 1959}

Pseudoparlatoria caucae Balachowsky, 1959:351-352 (fig.); BorCHSENIUS, 1966:162 (cat.); FonseCA, 1969:24.

Redescrição. Macho desconhecido. Escudo da fêmea subcircular, achatado, rugoso, fosco, marromclaro, diâmetro $1,1 \mathrm{~mm}$; exúvias apicais douradas (BALACHOWSKY, 1959).

Fêmea adulta oval, membranosa; tubérculo antenal com uma seta longa, espiráculos anteriores e posteriores sem glândulas; sem lobos abdominais pré-pigidiais. Pigídio com lóbulos muito pequenos: L1 arredondados; L2 bilobados; L3 reduzidos, confundidos com a margem do VI segmento. Um par de espinhos glandulares em forma de " $y$ " entre os L1; um espinho glandular com ápices simples entre L1 e L2 e outro entre L2 e L3, de cada lado, todos mais longos do que os lóbulos; antes de L3, espinhos glandulares reduzidos. Margem anterior aos lóbulos pigidiais levemente denticulada. Um macroconduto marginal entre os L1, um entre L1 e L2, dois entre L2 e L3 e três antes de L3, de cada lado das margens. Uma glândula submarginal, de cada lado, no VII segmento, de tamanho semelhante às marginais, demais glândulas um pouco menores, cerca de nove de cada lado, restritas ao pigídio. Ânus a $0,03 \mathrm{~mm}$ da margem pigidial. Glândulas circungenitais em quatro grupos: 1011 ântero-laterais, 9 póstero-laterais.

Material-tipo. Holótipo q. COLÔMBIA, Valle del Cauca: Navarro, margens do rio Cauca, 17.I.1957, A. Balachowsky col., ex. "planta epífita em tronco de Sapote" (MNHN 2571). O exemplar não se apresenta inteiro na lâmina, é possível observar apenas o abdome e parte do cefalotórax.

Localidade-tipo: Colômbia, Valle del Cauca: Navarro, 15 $\mathrm{km}$ do Valle del Cauca, margens do Rio Cauca.

Distribuição geográfica. Colômbia.

\section{Pseudoparlatoria circularis Lepage, 1942}

Pseudoparlatoria circularis LePage, 1942:176-177 (fig.); Vernalha, 1953:193 (cat.); Borchsenius, 1966:162 (cat.).

Redescrição. Escudo do macho alongado, em média, 1,43 $\mathrm{mm}$ de comprimento e 0,94 $\mathrm{mm}$ de largura, amarelo-claro, transparente; exúvia apical, da mesma cor do escudo. Escudo da fêmea subcircular, em média, 1,35 $\mathrm{mm}$ de comprimento e 1,3 mm de largura, marrom-escuro com orla externa amarela; exúvias excêntricas, amarelas.

Fêmea adulta subcircular, em média, 0,66 $\mathrm{mm}$ de comprimento e $0,54 \mathrm{~mm}$ de largura, membranosa, com exceção do pigídio. Tubérculo antenal com uma seta longa, espiráculos anteriores e posteriores sem glândulas, sem lobos abdominais pré-pigidiais. Pigídio com três pares de lóbulos pigidiais: L1 grandes, bem separados um do outro, com uma reentrância bem pronunciada de cada lado; L2 e L3 bilobados, pouco desenvolvidos. Um par de espinhos glandulares, em forma de " $\mathrm{y}$ ", entre os L1; um espinho glandular entre L1 e L2 e outro par entre L2 e L3, com ápice simples, de cada lado das margens, todos bem maiores que os lóbulos; espinhos glandulares reduzidos antes de L3. Margem anterior aos lóbulos pigidiais finamente serrilhada e esclerotizada. Sem macroconduto marginal entre os L1, um entre L1 e L2, dois entre L2 e L3 e um antes de L3. Grande quantidade de glândulas submarginais, menores que as marginais até os primeiros segmentos abdominais. Ânus a $0,02 \mathrm{~mm}$ da margem pigidial. Glândulas circungenitais em quatro grupos, raramente cinco: 0-2 mediano, 13-24 ânterolaterais, 14-23 póstero-laterais. Muitos microcondutos por todo o corpo.

Material-tipo. Aqui designado: lectótipo ?. BRASIL, São Paulo: Campos do Jordão, 12.XII.1941, H. S. Lepage col., ex. "planta silvestre" (IBSP); paralectótipos: 4ㅇ, 2 lâminas, mesmos dados do lectótipo (1 lâmina ret. MRGC 338); 6 escudos de $\subsetneq$, 2 lâminas; 3 escudos de ơ e 3 escudos de $\varsubsetneqq$ em uma folha, tubo de vidro (IBSP 802).

Distribuição geográfica. Brasil.

Discussão. Segundo LePAGE (1942), os escudos de machos e fêmeas medem respectivamente $0,8 \mathrm{~mm}$ e 1,2 $\mathrm{mm}$ de diâmetro, no material examinado são respectivamente $0,63 \mathrm{~mm}$ e $0,15 \mathrm{~mm}$, maiores. Segundo o mesmo autor, o comprimento da fêmea adulta é $0,8 \mathrm{~mm}$; no material examinado a média é $0,14 \mathrm{~mm}$ menor.

\section{Pseudoparlatoria constricta Fonseca, 1975}

Pseudoparlatoria constricta FonsECA, 1975:83 (fig.).

Redescrição. Macho desconhecido. Escudo da fêmea circular, diâmetro $1 \mathrm{~mm}$, pouco convexa, com uma série de caneladuras transversais, superfície lisa e luzidia, preta no centro, margem e próximo das exúvias mais claro, exúvias marginais marrom-claras (FONSECA, 1975).

Fêmea adulta subcircular, com acentuada constrição no ápice do protórax, em média, 0,56 mm de comprimento e $0,5 \mathrm{~mm}$ de largura, membranosa, exceto no pigídio, tubérculo antenal com uma seta longa; espiráculos anteriores e posteriores sem glândulas; lobos abdominais pré-pigidiais bem desenvolvidos, com grande quantidade de microcondutos. Pigídio arredondado, com três pares de lóbulos desenvolvidos: L1 tão longos quanto largos, margens lisas e ápice arredondado; L2 e L3 bilobados, ápice arredondado. Um par de espinhos glandulares em forma de " $y$ ", com leve entalhe na margem externa, entre os L1; um espinho glandular entre L1 e L2; outro entre os L2 e L3, em cada lado. Margem anterior 
aos lóbulos com pequenos dentes. Um macroconduto marginal entre os L1; um entre L1 e L2 e dois entre L2 e L3, de cada lado das margens. Macrocondutos submarginais muito pequenos, em grande quantidade, em todo o pigídio até os primeiros segmentos abdominais. Ânus a 0,05 mm da margem pigidial. Glândulas circungenitais em quatro ou cinco grupos: 0-3 mediano, 10-19 ântero-laterais, 13-19 póstero-laterais.

Material-tipo. Aqui designado: lectótipo §. BRASIL, São Paulo: Águas da Prata, III.1974, H. S. Lepage col., ex. Solanaceae (IBSP); paralectótipos: 24q, 2 lâminas, mesmos dados do lectótipo (MZSP 868) (1 retida MRGC 343); Rio Grande do Sul: Erebango, 19ł, 1 lâmina e escudos em material herborizado, 19.I.1978, N. F. Mattos col. (MZSP 877).

Distribuição geográfica. Brasil.

Hospedeiro. Solanaceae: planta silvestre.

\section{Pseudoparlatoria elongata Ferris, 1941}

Pseudoparlatoria elongata FERRIS, 1941b:SIII-316 (fig.); BorCHSENIUS, 1966:163 (cat.); Miller, 1996:78.

Redescrição. Escudo do macho semelhante ao da fêmea, menor, exúvia apical (FERRIs, 1941b). Escudo da fêmea alongado e estreito, marrom-claro ou palha, exúvia apical (FERRIS, 1941b).

Fêmea adulta oval alongada, em média, 1,1 $\mathrm{mm}$ de comprimento e $0,63 \mathrm{~mm}$ de largura, membranosa, exceto o pigídio, tubérculo antenal com duas setas longas, espiráculos anteriores e posteriores sem glândulas; sem lobos abdominais pré-pigidiais. Alguns microcondutos no cefalotórax e primeiros segmentos abdominais. Pigídio com três pares de lóbulos: L1 bem desenvolvidos, arredondados, com uma leve reentrância de cada lado; L2 bilobados, menores que L1, com os lobos mais ou menos de mesmo tamanho; L3 semelhantes a L2, porém menores. Espinhos glandulares em forma de "y"entre os L1; um espinho glandular simples entre L1 e L2 e outro entre L2 e L3, de cada lado das margens, todos maiores que os lóbulos; antes de L3 não se observam espinhos glandulares. Margem anterior aos lóbulos pigidiais com leve esclerotização. Sem macroconduto marginal entre os L1, um macroconduto marginal entre L1 e L2, dois entre L2 e L3, três antes de L3, de cada lado. Um macroconduto submarginal, no VII segmento, de cada lado, quase do mesmo tamanho dos marginais, demais macrocondutos um pouco menores, até os primeiros segmentos abdominais. Ânus a 0,04 mm da margem pigidial. Glândulas circungenitais em cinco grupos: 3-9 mediano, 12-19 ântero-laterais, 13-21 póstero-laterais.

Material-tipo. Aqui designado: lectótipo ₹. MÉXICO, Distrito Federal: México, Desierto de los Leones, 1926, G. F. Ferris col., ex. Pseudotsuga taxifolia (UCDC 348); paralectótipos: 5\&, 3 lâminas, mesmos dados do lectótipo (UCDC 348). Os síntipos ‡ (VPIC) e $\subsetneq$ (USNM) não foram examinados.

Distribuição geográfica. México.

Hospedeiro: Pinaceae. Pseudotsuga taxifolia (Poir.)

Britt.
Discussão. Segundo FERRIS (1941b), o comprimento do corpo da fêmea é $1,25 \mathrm{~mm}$; a média do comprimento do material examinado é $0,15 \mathrm{~mm}$ menor.

\section{Pseudoparlatoria fusca Ferris, 1941}

Pseudoparlatoria fusca FerRIs, 1941b:SIII-317 (fig.); BALACHOWSKY, 1959:354; Borchsenius , 1966:163 (cat.); Miller , 1996:78.

Redescrição. Escudo do macho oval, exúvia terminal (FERris, 1941b). Escudo da fêmea oval, pouco convexo, rugoso, formado por camadas concêntricas, exúvias submarginais (FERRIS, 1941b).

Fêmea adulta oval, em média, 0,56 $\mathrm{mm}$ de comprimento e $0,46 \mathrm{~mm}$ de largura, tubérculo antenal com uma seta longa; espiráculos anteriores e posteriores sem glândulas, três pequenos lobos abdominais pré-pigidiais. Pigídio com três pares de lóbulos: L1 arredondados, bem separados, L2 e L3 pequenos e bilobados. Um par de espinhos glandulares em forma de "y" entre os L1; entre L1 e L2 e entre L2 e L3, um espinho glandular, com ponta simples, de cada lado das margens, todos mais longos que os lóbulos; espinhos glandulares curtos antes de L3. Margem anterior aos lóbulos pigidiais com alguns dentículos. Um macroconduto marginal entre os L1, um entre L1 e L2, dois entre L2 e L3, três antes de L3, de cada lado. Macrocondutos submarginais desde os primeiros segmentos abdominais, nos segmentos $\mathrm{V}$ e entre os segmentos VI e VII menores do que os marginais, em grupos definidos, no VII segmento quase do mesmo tamanho dos marginais. Ânus a 0,04 mm da margem pigidial. Glândulas circungenitais em quatro ou cinco grupos: 0-3 mediano, 5-14 ântero-laterais, 6-17 pósterolaterais.

Material-tipo. Aqui designado: lectótipo \&. MÉXICO, Vera Cruz-Llave: Puerto México, 1926, R.F. Wilkey col., ex. planta indeterminada (UCDC 1009); paralectótipos: 16‡, 8 lâminas, mesmos dados do lectótipo (UCDC 1009). Os síntipos depositados em VPIC e USNM não foram examinados.

Material examinado. MÉXICO: La Providencia, 4\&, 1 lâmina, sem data, sem coletor, (UCDC 356). PANAMÁ, Chiriqui: Cerro Punta, El Volcán, 3థ, 1 lâmina, sem data, sem coletor (UCDC); 39, 1 lâmina, 1938, T. T. Howard col. (UCDC). COLÔMBIA, Amazonas: Leticia, $\&$, 14.III.1957, A. Balachowsky col. (UCDC). BRASIL, Bahia: Bacia do Rio Una, 14థ, 2 lâminas, 10.VII.1942, sem coletor (UCDC 1262)(1 ret. MRGC 344); 8\&, 1 lâmina, 09.X.1942, sem coletor (UCDC 1017). URUGUAI, Rio Yi, 3q, 1 lâmina IX. 1921, P. Schurman col., ex. Maytenus ilicifolia (USNM)

Distribuição geográfica. México, Colômbia, Panamá, Brasil, Uruguai.

Hospedeiro. Maytenus ilicifolia (Schrad.) Planch (Celastraceae); planta indeterminada.

\section{Pseudoparlatoria fusiformis Fonseca, 1969}

Pseudoparlatoria fusiformis FonseCA, 1969:22-24 (fig.).

Redescrição. Macho desconhecido. Escudo da fêmea subcircular, em média, 1,61 mm de comprimento e 1,44 mm de largura, membranoso, quase transparente, amarelo-claro; exúvias da mesma cor da parte secretada do escudo, na margem apical. 
Fêmea adulta com cefalotórax semicircular, com uma constrição no metatórax, abdome estreito e alongado, em média, $0,96 \mathrm{~mm}$ de comprimento e $0,69 \mathrm{~mm}$ de largura, toda esclerotizada, tubérculo antenal com duas setas, espiráculos anteriores e posteriores sem glândulas, sem lobos abdominais pré-pigidiais. Uma série de glândulas filiformes nas margens laterais do cefalotórax até o abdome. Pigídio com três pares de lóbulos bem desenvolvidos: L1 bem separados, arredondados no ápice, com um entalhe de cada lado; L2 e L3 bilobados, quase do mesmo tamanho. Um par de espinhos glandulares, em forma de "y", entre os L1; entre L1 e L2 e entre L2 e L3, um espinho glandular, de cada lado, com ápice simples, mais longo que os lóbulos; antes de L3, espinhos glandulares reduzidos. Margem anterior aos lóbulos finamente serrilhada. Sem macroconduto marginal entre os L1, um entre L1 e L2, dois entre L2 e L3, três antes de L3, de cada lado. Macroconduto submarginal, no VII segmento, quase do mesmo tamanho dos marginais; nos segmentos anteriores, pouco menores, restritos ao pigídio. Ânus a $0,03 \mathrm{~mm}$ da margem do pigídio. Glândulas circungenitais em quatro grupos: 8-20 ânterolaterais, 9-17 póstero-laterais.

Material-tipo. Aqui designado: lectótipo @. BRASIL, São Paulo: Serra da Cantareira, VI.1957, J. P. da Fonseca col., ex. plantas silvestres (IBSP 851); paralectótipos: 9ף, 6 lâminas, mesmos dados do lectótipo (IBSP) (1 ret. MRGC 340); 13q, 4 lâminas (MZSP); escudos em material herborizado, 2 tubos de vidro.

Material examinado. BRASIL, São Paulo: São Paulo, Parque Siqueira Campos, 5§, 1 lâmina, VI.1957, J. P. da Fonseca col., ex. Casearia sylvestris (MZSP 15); Morumbi, 18§, 5 lâminas, II.1961, J. P. da Fonseca col., ex. Myrtaceae (MZSP 157); Jardim da Luz, VII.1976, J. P. da Fonseca col., ex. Casearia sp. (J.P. da Fonseca), 8̊, 1 lâmina (MZSP 419); Jardim da Luz, 17๕, 2 lâminas, XI.1976, ex. Casearia sylvestris (MZSP 425); Jardim da Luz, 5\&, 1 lâmina, XII.1976, J. P. da Fonseca col., ex. Myrcia jaboticaba (MZSP 444); Parque Siqueira Campos, 4\&, 1 lâmina, V-1979, J. P. da Fonseca col., ex. Casearia sp. (MZSP 520); 3\$, 3 lâminas, 18.VII.1962, S.W. Brown col., ex. Myrcia jaboticaba (UCDC 162); 11, 3 lâminas, sem data., sem coletor (IBSP 120).

Distribuição geográfica. Brasil.

Hospedeiro. Flacourtiaceae: Casearia sylvestris Camb., Casearia sp.; Myrtaceae: Myrcia jaboticaba Berg.; plantas silvestres.

Discussão. Semelhante a P. mammata e P. sculpta pela forma do corpo, difere destas por não apresentar lobos abdominais pré-pigidiais, macrocondutos submarginais restritos ao pigídio e ausência de macroconduto marginal entre os lóbulos medianos.

\section{Pseudoparlatoria lentigo Ferris, 1942}

Pseudoparlatoria lentigo Ferris, 1942:SIV-414 (fig.); Borchsenius, 1966:163 (cat.).

Redescrição. Macho desconhecido. Escudo da fêmea circular, achatado, membranoso, amarelo, exúvias excêntricas (FERRIS, 1942).

Fêmea adulta oval, em média, $0,78 \mathrm{~mm}$ de comprimento e $0,6 \mathrm{~mm}$ de largura, membranosa exceto pigídio, tubérculos antenais com uma seta longa e duas mais curtas, espiráculos anteriores e posteriores sem glândulas, um lobo abdominal pré-pigidial desenvolvido.
Margem anterior aos lóbulos pigidiais levemente esclerotizada. Pigídio com três pares de lóbulos: L1 arredondados, bem separados; L2 e L3 bilobados. Um par de espinhos glandulares, em forma de " $y$ "; entre os L1; entre L1-L2 e entre L2-L3 um espinho glandular, de cada lado das margens, longo, com ápice simples; antes de L3, espinhos glandulares reduzidos. Um macroconduto marginal entre os L1, um entre L1 e L2, dois entre L2 e L3, três antes de L3, de cada lado. Macrocondutos submarginais no VII e VI segmentos, quase do mesmo tamanho dos marginais; demais menores, restritos ao pigídio. Ânus a $0,05 \mathrm{~mm}$ da margem pigidial. Glândulas circungenitais em quatro grupos: 10-12 ântero-laterais, 12-14 póstero-laterais.

Material-tipo. Aqui designado: lectótipo §. PANAMÁ, Chiriqui: $\&$, 1938, G. F. Ferris col., ex. planta indeterminada (UCDC 83); paralectótipos: Armuelles, 6‡, 2 lâminas, 1938, G. F. Ferris col. (UCDC 111). Os síntipos $q$ (VPIC) e $\subsetneq$ (USNM) não foram examinados.

Discussão. Segundo FERRIS (1942), o comprimento do corpo da fêmea adulta é $0,09 \mathrm{~mm}$; o material examinado é menor.

\section{Pseudoparlatoria maculata Ferris, 1942}

Pseudoparlatoria maculata FERRIS, 1942:SIV-415 (fig.); Borchsenius, 1966:163 (cat.); Miller, 1996:78.

Redescrição. Escudo do macho alongado, semelhante na cor e textura ao da fêmea, exúvia de posição apical (FERRIS, 1942). Escudo da fêmea circular, achatado, textura membranosa; exúvias muito grandes de posição submarginal, amarelo-claras com uma mancha escura na $1^{\underline{a} \mathrm{a}}$ e $2^{\mathrm{a}}$ exúvias (FerRIS, 1942).

Fêmea adulta oval, em média, $0,5 \mathrm{~mm}$ de comprimento e $0,41 \mathrm{~mm}$ de largura, espiráculos anteriores e posteriores sem glândulas, tubérculos antenais com uma seta, dois lobos abdominais pré-pigidiais. Pigídio com três pares de lóbulos: L1 bem afastados um do outro, arredondados; L2 e L3 bilobados. Um par de espinhos glandulares em forma de " $y$ " entre os L1; entre L1-L2 e entre L2-L3, um espinho glandular com ápice simples, em cada lado; demais espinhos glandulares reduzidos. Margem anterior aos lóbulos quase lisa. Um macroconduto marginal entre os L1, um entre L1 e L2, outro entre L2 e L3, três antes de L3. Macrocondutos submarginais, no VII segmento, quase do mesmo tamanho dos marginais; demais menores, restritos ao pigídio. Ânus a $0,04 \mathrm{~mm}$ da margem pigidial. Glândulas circungenitais em quatro grupos: 7-12 ântero-laterais, 6-10 pósterolaterais.

Material-tipo. Aqui designado: lectótipo §. MÉXICO, Guerrero: La Providencia, 1926, R. F. Wilkey col. (UCDC 356); paralectótipos: 4\&, em 2 lâminas, mesmos dados do lectótipo (UCDC 356). Os síntipos do USNM e VPIC não foram examinados.

Pseudoparlatoria mammata (Ferris, 1941) comb. nov.

Malleolaspis mammata FERRIS, 1941b:SIII-291 (fig.); BORCHSENIUS, 1966:162 (cat.). 
Redescrição. Escudo do macho não encontrado (FERris, 1941b). Escudo da fêmea adulta subcircular, membranoso, achatado, amarelo, com exúvia excêntrica (FERRIS, 1941b).

Fêmea adulta, em média, 0,84 mm de comprimento e 0,64 mm de largura, cefalotórax semicircular com uma constrição no metatórax, margens laterais do metatórax e primeiro segmento abdominal com lobos pontiagudos seguidos de mais três lobos abdominais pré-pigidiais, tubérculo antenal com uma seta longa, espiráculos anteriores e posteriores sem glândulas. Pigídio com três pares de lóbulos bem desenvolvidos: L1 largos, uma reentrância de cada lado e ápices arredondados; L2 e L3 bilobados. Antes de L3, a margem é serrilhada. Entre os lóbulos medianos há um par de espinhos glandulares em forma de "y"; entre L1 e L2 e entre L2 e L3, um espinho glandular, com ponta simples, de cada lado das margens, mais longo do que os lóbulos; demais espinhos glandulares reduzidos. Um macroconduto marginal entre os L1, um entre L1 e L2, dois entre L2 e L3 e dois antes de L3, de cada lado. Dois macrocondutos submarginais, quase do mesmo tamanho dos marginais, próximos ao ânus; os demais um pouco menores, até os primeiros segmentos abdominais. Ânus a $0,04 \mathrm{~mm}$ da margem pigidial. Glândulas circungenitais em quatro grupos: 310 ântero-laterais, 7-8 póstero-laterais. Grande quantidade de microcondutos nos lobos abdominais pré-pigidiais e no pigídio.

Material-tipo. Aqui designado: lectótipo §. PANAMÁ, Chiriqui: Armuelles, sem data, Ferris col., ex. Leguminosae (UCDC 550). O síntipo do USNM não foi examinado; o curador informou que o exemplar, na lâmina, está difícil de ser observado.

Material examinado. PANAMÁ, Chiriqui: Armuelles, 4\%, 1 lâmina, sem data, Ferris col., ex. planta indeterminada (UCDC 340 B). BRASIL, São Paulo: São Paulo, 15\$, 1 lâmina, IV.1963, J. P. da Fonseca col., ex. Cynara cardunculus (MZSP 183); 7థ, 3 lâminas, VII. 1963, J. P. da Fonseca col., planta silvestre (MZSP 197) (1 ret. MRGC 346).

Distribuição geográfica. Panamá, Brasil.

Hospedeiros. Compositae: Cynara cardunculus L.; Leguminosae; planta indeterminada.

Discussão. Esta espécie é semelhante a $P$. fusiformis e a $P$. sculpta pela forma do cefalotórax e constrição no metatórax; diferencia-se de $P$. fusiformis pela presença de um macroconduto marginal entre os lóbulos medianos e de $P$. sculpta pela presença de lobos pontiagudos no metatórax e primeiro segmento abdominal.

\section{Pseudoparlatoria noacki Cockerell, 1898} (Figs. 1, 2)

Pseudoparlatoria noacki CoCKerell, 1898a:201, 1898b:42; HeMPEL, 1900:511; Fernald, 1903:300 (cat.); MaCGillivray, 1921:314; LePage, 1938:419 (cat.); Borchsenius, 1966:163 (cat.); Silva et al., 1968:180 (cat.).

Redescrição. Escudo do macho menor que o da fêmea, oval, achatado, branco semitransparente, exúvia grande, esverdeada com mancha amarela COCKERELL (1898a,b). Escudo da fêmea circular ou subcircular; 2,06 mm de comprimento, $1,90 \mathrm{~mm}$ de largura, achatado ou levemente convexo, marrom-claro com as margens brancas ou esbranquiçadas; exúvias excêntricas amarelas. Fêmea adulta oval, em média, $0,83 \mathrm{~mm}$ de comprimento e $0,56 \mathrm{~mm}$ de largura, tubérculo antenal com uma seta longa e duas outras um pouco mais curtas e finas, espiráculos anteriores e posteriores sem glândulas, três lobos abdominais pré-pigidiais. Pigídio com três pares de lóbulos desenvolvidos: L1 grandes, bem afastados um do outro, ápice arredondado e uma reentrância de cada lado, L2 e L3 bilobados. Margem anterior a L3 com fina denticulação. Um par de espinhos glandulares em forma de "y" entre os L1, um espinho glandular simples entre L1 e L2 e outro entre L2 e L3, de cada lado das margens; antes de L3 não se observam espinhos glandulares. Um macroconduto marginal entre os L1, um entre L1 e L2, dois entre L2 e L3, três antes de L3, de cada lado das margens. Um macroconduto submarginal, de cada lado, no VII segmento, quase do mesmo tamanho dos marginais; os demais macrocondutos submarginais menores, até os primeiros segmentos abdominais. Ânus a 0,04 mm da margem pigidial. Cinco grupos de glândulas circungenitais: 8-11 mediano, 15-25 ântero-laterais, 9-22 póstero-laterais.

Material-tipo. Aqui designado: lectótipo \&. BRASIL, São Paulo: Campinas, I.1898, F. Noack col., ex. Nectandra sp. (USNM); paralectótipos: 2q, 1 lâmina, mesmos dados do lectótipo (USNM); 3‡, 1 lâmina (BMNH 249). A lâmina da coleção BMNH 249 encontra-se em estado muito precário para observação dos exemplares.

Material examinado. BRASIL, São Paulo: Campinas, 2 escudos f, tubo de vidro, I.1898, F. Noack col., ex. planta silvrestre (MZSP 217); 29, 3 escudos, 1 lâmina, sem data, sem coletor (BMNH).

Distribuição geográfica. Brasil.

Hospedeiro. Lauraceae: Nectandra sp.; plantas silvestres.

Discussão. Segundo CocKerell (1898a), o escudo da fêmea mede 1,67 mm de diâmetro; os examinados são maiores.

\section{Pseudoparlatoria occultata (Hempel, 1937)}

\section{Diaspis occultata HEMPEL, 1937:28.}

Pseudoparlatoria occultata; LePage \& GiannotTI, 1943:334-335 (fig.); Vernalha, 1953:193 (cat.); Borchsenius, 1966:163 (cat.); SiLVA et al., 1968:180 (cat.)

Redescrição. Macho desconhecido. Escudo da fêmea circular; 1,5 mm de diâmetro, superfície dorsal um pouco áspera e convexa, marrom no dorso e branco na face inferior (HEMPEL, 1937)

Fêmea adulta oval, em média, 0,94 $\mathrm{mm}$ de comprimento e $0,79 \mathrm{~mm}$ de largura, tubérculo antenal com uma seta curta e outra longa, espiráculos anteriores e posteriores sem glândulas, sem lobos abdominais prépigidiais. Pigídio com três pares de lóbulos: L1 mais largos que longos, bem afastados um do outro, ápice arredondado com uma reentrância de cada lado das margens; L2 bilobados; L3 muito reduzidos. Entre os L1, um par de espinhos glandulares largos, em forma de "y"; um espinho glandular com ápice simples entre L1 e L2 e outro entre L2 e L3, de cada lado; demais espinhos glandulares inconspícuos. Antes de L3, três pequenas 

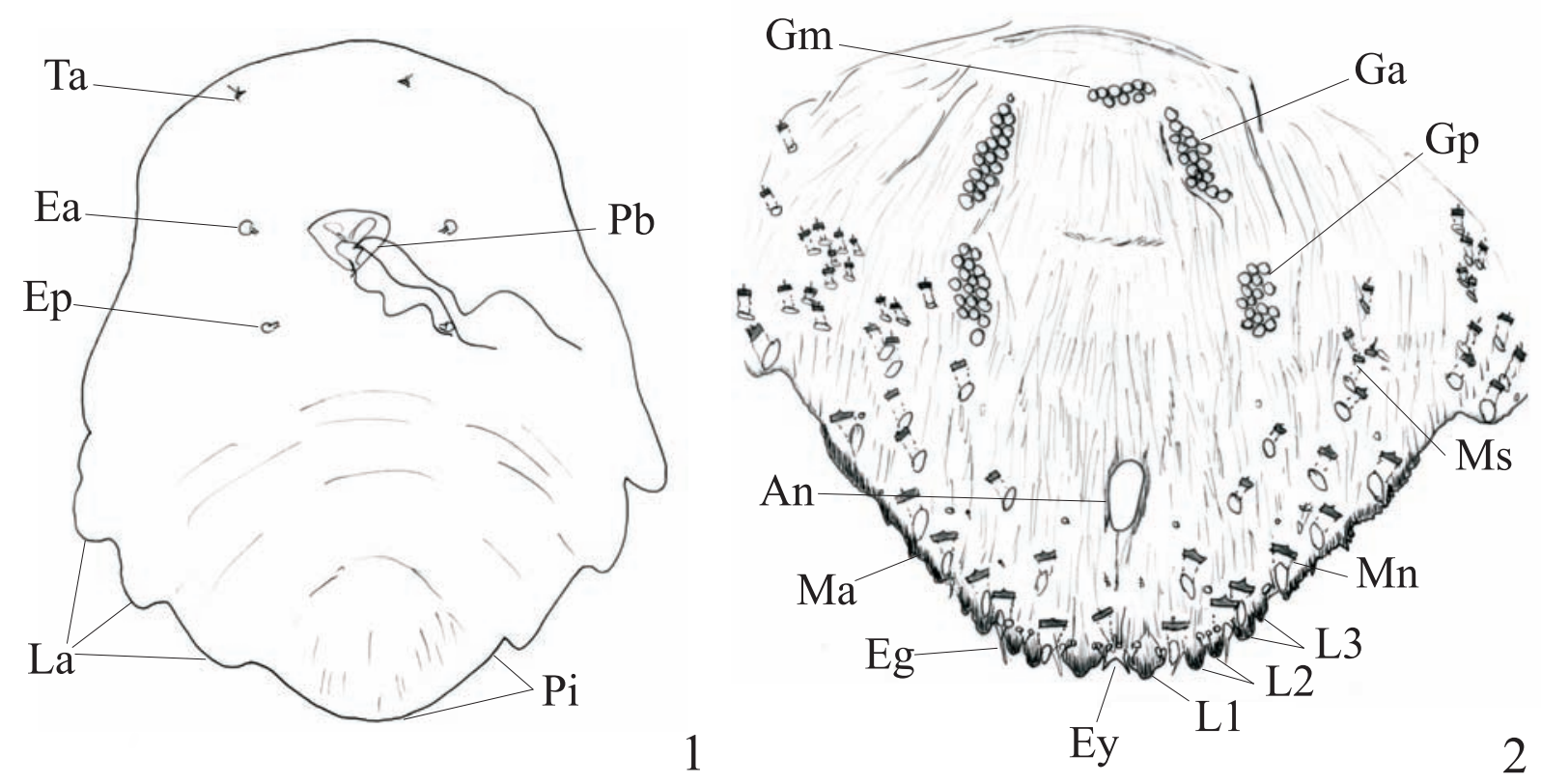

Figs. 1-2. Desenho esquemático de Pseudoparlatoria noacki Cockerell, 1898. 1, corpo de fêmea adulta, 0,83 mm de comprimento (Ea, espiráculo anterior; Ep, espiráculo posterior; La, lobos abdominais pré-pigidiais; $\mathrm{Pb}$, peças bucais; Pi, pigídio; Ta, tubérculo antenal); 2 , pigídio (An, ânus; Eg, espinho glandular; Ey, par de espinhos glandulares em forma de "y"; Ga, grupo de glândulas circungenitais ânterolaterais; Gm, grupo de glândulas circungenitais medianas; Gp, grupo de glândulas circungenitais póstero-laterais; L1, lóbulo mediano; L2, segundo lóbulo; L3, terceiro lóbulo; Ma, margem anterior; Mn, macroconduto marginal; Ms, macroconduto submarginal).

saliências esclerotinizadas. Sem macroconduto marginal entre L1, um entre L1 e L2, dois entre L2 e L3, três antes de L3. Um macroconduto submarginal, de cada lado, no VII segmento, quase do mesmo tamanho dos marginais; demais macrocondutos submarginais menores, até os primeiros segmentos abdominais. Ânus a $0,06 \mathrm{~mm} \mathrm{da}$ margem. Glândulas circungenitais em cinco grupos: 6-10 mediano, 12-21 ântero-laterais, 12-23 póstero-laterais.

Material-tipo. Aqui designado: lectótipo \&. BRASIL, São Paulo: São Paulo, 1.IX.1936, J. P. da Fonseca col., ex. Baccharis sp. (IBSP 719); paralectótipos: 11†, 2 lâminas, mesmos dados do lectótipo (IBSP 719).

Material examinado. BRASIL, 4ॄ, 1 lâmina, sem data., sem coletor, ex. Baccharis sp. (MZSP); 12f, 1 lâmina, sem data, J. P. da Fonseca col., ex. Baccharis sp. (MZSP).

Distribuição geográfica. Brasil.

Hospedeiro: Compositae: Baccharis sp.

Discussão. Segundo Hempel (1937), as fêmeas adultas medem cerca de 1,28 mm de comprimento e 1,14 mm de largura; a média dos exemplares examinados foram respectivamente $0,34 \mathrm{~mm}$ e $0,35 \mathrm{~mm}$ menores. LEPAGE \& GiANNOTTI (1943) examinaram o material-tipo e transferiram a espécie para Pseudoparlatoria, sem nada acrescentar.

\section{Pseudoparlatoria ostreata Cockerell, 1892}

Pseudoparlatoria ostreata CoCKerell, 1892:136; FerRIS,1942:SIV416 (fig.); Balachowsky, 1954:256; BorChSENIUS, 1966:163 (cat.); Silva et al., 1968:180 (cat.); Claps \& GonZales, 1995:34; Miller, 1996:78.

Diaspis tricuspidata LEONARDI, 1914:192.

Pseudoparlatoria tricuspidata; LINDINGER, 1928:107.

Pseudoparlatoria parlatorioides FERRIS, 1937:SI-117.

Redescrição: Escudo do macho alongado, textura e cores semelhantes ao da fêmea, exúvia apical (FERRIS,
1942). Escudo da fêmea arredondado, 1,2 mm de diâmetro, membranoso, cinza-escuro, exúvia excêntrica (FERRIs, 1942).

Fêmea adulta oval, em média, 0,94 mm de comprimento e $0,79 \mathrm{~mm}$ de largura, tubérculo antenal com uma seta longa e duas curtas e finas, espiráculos anteriores e posteriores sem glândulas, com lobos abdominais pré-pigidiais pouco desenvolvidos. Pigídio com três pares de lóbulos pouco desenvolvidos: L1 grandes, bem separados um do outro, com uma reentrância em cada lado, forte esclerotização na base; L2 pequenos e bilobados; L3 representados por pequena ponta. Entre os L1, um par de espinhos glandulares em forma de "y"; um espinho glandular, com ápice simples, entre L1 e L2, outro entre L2 e L3, de cada lado das margens; antes de L3, vários espinhos glandulares pequenos. Sem macroconduto marginal entre os L1, um entre L1 e L2, dois entre L2 e L3, três antes de L3, de cada lado. Um macroconduto submarginal, quase do mesmo tamanho dos marginais, no VII segmento, de cada lado; demais macrocondutos submarginais menores, até o II segmento abdominal. Ânus a 0,04 $\mathrm{mm}$ da margem do pigídio. Glândulas circungenitais em quatro ou cinco grupos: 0-6 mediano, 11-27 ântero-laterais, 8-19 pósterolaterais. Microcondutos restritos ao pigídio.

Material-tipo. Aqui designado: lectótipo . JAMAICA, Kingston (BMNH): paralectótipos: 20£, 2 lâminas, mesmos dados do lectótipo (BMNH).

Material examinado. USA, Texas: Brownsville, 6 6,3 lâminas, sem data, sem coletor, ex. Parkinsonia aculeata (UCDC T-702); 12\&, 1 lâmina, sem data, sem coletor, (UCDC); REPÚBLICA DOMINICANA, Distrito Nacional: Santo Domingo, 2\&, 1 lâmina, 25.XII.1911, W. V. Tower col., ex. Ruda sp. (VPIC); PORTO RICO, 9‡, 1 lâmina, sem data, sem coletor, ex. indeterminado (UCDC); 6‡, 3 lâminas, 1924, G. N. Wolcort col., ex. Piper medium (UCDC); JAMAICA, Kingston: 4\&, 1 
lâmina, sem data, sem coletor (USNM); 6థ, 3 lâminas, 12.XI.1891, J. D. A. Cockerell col., ex. Acalypha marginata (USNM); $8 \nsubseteq, 3$ lâminas, 10.III.1892, J. D A. Cockerell col. (USNM); 3 \&, 3 lâminas, 28.VI.1962, S. W. Brown col., ex. Piper nigrum (UCDC 120); Saint Ann: Ocho Rios, 5£, 5 lâminas, 16.VIII. 1962, S. W. Brown col., ex. planta indeterminada (UCDC 179); Hanover: Lucea, 39 , 3 lâmina, 19.VIII.1962, S. W. Brown col., ex. Coleus sp. (UCDC 182); GUATEMALA, 2f, 1 lâmina, 31.VII.1936, R. D. Clemens col., ex. Cattleya bowringeana (UCDC); BRASIL, São Paulo: Serra da Cantareira, 12q, 3 lâminas, VIII.1965, J. P. da Fonseca col., ex. Merostachys sp. (MZSP 235); CHILE, Región Metropolitana de Santiago: acima Rio Colorado, 3̊, 1 lâmina, 1.II.1902, Hastings col., (USNM 530305); ARGENTINA, Salta: 4\&, 1 lâmina, 23.II.1987, L. Claps col., ex. Tillandsia sp. (IMLA C25.87); Catamarca: San Fernando, 4ঙ, 2 lâminas, 20.XII.1986, L. Claps col., ex. Suaeda divaricata (IMLA - C56.86); Quebrada La Cébila, \&, 04.XII.1994, L. Claps, M de Haro col., ex. Aspidosperma quebracho-blanco (IMLA C-13.94); Santiago del Estero: Loreto, 18.XI.1988, \&, L. Claps, M. de Haro, A. Chaloup col., ex. Aspidosperma quebracho-blanco (IMLA C55.88) Clodomira, 3q, 1 lâmina, 21.XI.1988, L. Claps, M. de Haro, A. Chaloup col., ex. Aspidosperma quebracho-blanco (IMLA C54.88); Monte Quemado, 6̊, 2 fêmea, 18.II.1996, L. Claps, M. de Haro, P. Gonzalez, P. Zamudio col., ex. Aspidosperma quebracho-blanco (IMLA C10.96); Ojo de Agua, $\&$, 2.XII.1994, L. Claps, M. E. de Haro col., ex. Aspidosperma quebracho-blanco (IMLA C 21-94); Baez, \&, 2.XII.1994, L. Claps, M. E. de Haro col., ex. Aspidosperma quebracho-blanco (IMLA C- 22.94); Termas de Rio Hondo, Dique Frontal, f, 03.X.1995, L. Claps col., ex. Aspidosperma quebracho-blanco (IMLA C-28.95); Tucumán: Santa Bárbara, 3\&, 1 lâmina, 26.II.1995, L. Claps, M.E. de Haro, P. González col., ex. Cassia erecta (IMLA 44-95); Ticucho, 119, 3 lâmina, 6.IV.1985, A. Terán col., ex. Aspidosperma quebrachoblanco (IMLA -C9.85); Arroyo Ampinga, 2f, 1 lâmina, 13.X.1988, L. Claps col., ex. Prosopis alba (IMLA -C17.88a); Arroyo Ampinga, 13.X.1988, ex. Prosopis alba (L.Claps), \& (IMLA - C17.88b); Colalao del Valle, Yocavil, 4\&, 1 lâmina, 23.III.1993, L.Claps, M. de Haro, M.C.G. de Willink col., ex. Cercidium praecox (IMLA C12.93); Tapia, 2q, 1 lâmina, 25.II.1086, L. Claps col., ex. Aspidosperma quebracho-blanco (IMLA C-28.86); La Rioja: cuesta La Aguadita, Angulos, 4\&, 1 lâmina, 4.II.1987, L. Claps col., ex. Cassia aphylla (IMLA C8.87); Baldecitos, Talampaya, 2\&, 1 lâmina, 22.IX.1991, L. Claps, M. de Haro, M. I. Zamar col., ex. Senna sp. (IMLA C56.91); Neuquén: Villa El Chocón, 2q, 1 lâmina, 8.XII.1987, L. Claps col., ex. Cercidium sp. (IMLA C76.87).

Distribuição geográfica. Alemanha, França, Nigéria, Camarões, Senegal, Guiné, Serra Leoa, EUA, México, Cuba, República Dominicana, Porto Rico, Haiti, Jamaica, Guatemala, Venezuela, Guiana, Brasil, Equador, Chile, Argentina.

Hospedeiros. Apocynaceae: Aspidosperma quebracho-blanco Schelechtendal; Bromeliaceae: Tillandsia sp.; Caricaceae: Carica sp., Carica papaya L.; Cercidium sp., Cercidium praecox; Chenopodiaceae: Suaeda divaricata Moq.; Ephedraceae: E. andina; Euphorbiaceae: Acalypha marginata Spreng., Acalypha wilkesiana Muell.; Geraniaceae: Pelargonium sp.; Gramineae: Merostachys sp.; Leguminosae: Bauhinia sp., Cassia aphylla Cav., Cassia stricta Schrank, Parkinsonia aculeata L., Prosopis alba Griseb.; Piperaceae: Piper medium Jacq., Piper nigrum L.; Orchidaceae: Cattleya sp., Cattleya bowringeana Veitch., Cordula sp., Epidendrum sp., Laelia sp., Oncidium sp.; Pelargonium sp.; Pentas sp.; Pinus sp; Solanaceae: Cestrum sp., Cestrum nocturnum L., Solanum sp., Solanum seaforthianum Andr.

Discussão. Pseudoparlatoria ostreata é a espécietipo do gênero. Semelhante a Pseudoparlatoria parlatorioides (Comstock, 1883) e P. serrulata Townsend $\&$ Cockerell, 1898 pela forma dos lóbulos pigidiais. Difere de $P$. parlatorioides por apresentar macrocondutos submarginais desde o pigídio até o segundo segmento abdominal, enquanto que em $P$. parlatorioides os macrocondutos estão confinados ao pigídio e a abertura anal mais afastada da margem do mesmo. Difere de $P$. serrulata por apresentar os macrocondutos submarginais próximos dos marginais, enquanto que em $P$. serrulata os macrocondutos submarginais estão mais afastados dos marginais ficando uma zona livre de poros entre eles (FERRIS, 1942). A abertura anal de P. ostreata está mais afastada 0,01 $\mathrm{mm}$ da base dos lóbulos medianos do que as outras duas espécies.

\section{Pseudoparlatoria parlatorioides (Comstock, 1883)}

Aspidiotus parlatorioides Coмsтоск, 1883:64

Pseudoparlatoria pusilla GreEN, 1922:1010; FERRIS, 1942: SIV417 (sin.).

Pseudoparlatoria parlatorioides; COCKERELL, 1897:383, 1898c:503; Hempel, 1900:511; 1912:52;. MacGillivray, 1921:314; LePage, 1938:419; FERRIS, 1942:SIV-417 (fig.); LIZER Y TRELLES, 1942:234 Vernalha, 1953:194; Balachowsky, 1954:256; McKenzIE, 1956:35, 155; Borchsenius, 1966:164; Silva et al., 1968:180; Corseuil \& Silva, 1971:111; Claps \& GonZalez, 1995:34; Miller, 1996:78.

Redescrição. Escudo do macho alongado, 1,12 mm de comprimento, 0,56 $\mathrm{mm}$ de largura, marrom-claro, membranoso; exúvia amarela, apical. Escudo da fêmea subcircular ou oval, 1,29 $\mathrm{mm}$ de comprimento, $0,90 \mathrm{~mm}$ de largura, achatado, membranoso, marrom-claro; exúvias da mesma cor, excêntricas.

Fêmea adulta oval, em média $0,67 \mathrm{~mm}$ de comprimento e $0,54 \mathrm{~mm}$ de largura, tubérculo antenal com uma seta longa, espiráculos anteriores e posteriores sem glândulas, sem lobos abdominais pré-pigidiais. Pigídio com três pares de lóbulos: L1 bem desenvolvidos, afastados um do outro, com uma reentrância de cada lado; L2 e L3 pequenos, bilobados. Um par de espinhos glandulares em forma de " $y$ " entre os L1; um espinho glandular de ápice simples, mais longo do que os lóbulos, entre L1-L2 e outro entre L2-L3, de cada lado; antes de L3, espinhos glandulares curtos. Margem anterior aos lóbulos pigidiais pouco esclerotizada e serrilhada. Sem macroconduto marginal entre os L1; um entre L1-L2; dois entre L2-L3 e três antes de L3, de cada lado. Um macroconduto submarginal, tamanho semelhante aos marginais, no VII segmento abdominal; demais macrocondutos submarginais menores, cerca de oito de cada lado, restritos ao pigídio. Ânus a 0,03 mm da margem do pigídio. Glândulas circungenitais em quatro ou cinco grupos: 0-2 mediano, 5-15 ântero-laterais, 5-12 pósterolaterais.

Material-tipo. Aqui designado: lectótipo §. USA, Florida: Fort George [Island], 1883, ex. Persea carolinensis (USNM 224); paralectótipos: 3̊, 2 lâminas, mesmos dados do lectótipo (USNM 224).

Material examinado. SRI LANKA, Peradeniya, $\mathscr{q}$, sem data, R. S. Weglum col., ex. Theobroma cacao (UCDC); USA, California: Sawtelle, 7\&, 1 lâmina, 9.VII.1937, L. E. Myers col., ex. Cyprepidium sp. (UCDC); Larkspur, \&, 30.IX.1943, J. B Steinweden col., ex. Cypripidium sp. (UCDC); Texas: New Braunfels, 3†, 2 lâminas, 17.XI.1919, sem coletor, ex. "coral bean" 
(UCDC); Florida: Lake City, 5q, 1 lâmina, 12.XII.1897, sem coletor, Persea carolinensis (VPIC); 2\&, 1 lâmina, 19.VII.1934, R. H. Bremen col., ex. "Palmetto" (UCDC); MÉXICO, 3̧, 1 lâmina, sem data, Ferris col. (UCDC 300); 6‡, 1 lâmina, sem data, V. C. Minahtlum col., ex. Ceiba sp. (UCDC 432); 4ł, 1 lâmina, sem data, Ferris col. (UCDC 435); 2q, 1 lâmina, sem data, sem coletor (UCDC 1006); Aguililla, 4q, 2 lâminas, sem data, Ferris col., ex. Anona sp. (UCDC 240); 29, 1 lâmina, sem data, Ferris col., ex. Ficus sp. (UCDC 792); Manzanillo, 2q, 1 lâmina, ex. Cynometra oaxacuna (UCDC 754); Orizaba, 3q, 2 lâminas, sem data, sem coletor, ex. Myrtle sp. (UCDC F2069); Chevela, sem data, G. F. Ferris col., ex. Jacquinia sp. (UCDC 80); Carrizal, 4q, 2 lâminas, sem data, sem coletor, ex. planta indeterminada (UCDC 32); 2 \&, 1 lâmina, sem data, sem coletor, ex. "guayabilla" (UCDC 341); Rosario, Linalva, 4q, 2 lâminas, sem data, sem coletor (UCDC 435); Baja California: Acapulco, 3̧, 1 lâmina, sem data, G. F. Ferris col., ex. "cocos" (UCDC 339); 4F, 2 lâminas, sem data, G. F. Ferris col. (UCDC 760); $\subsetneq$ sem data, F. Guaron col., ex. Palmae (UCDC); Água Caliente, 5థ, 3 lâminas, VII. 1919, G. F. Ferris col., ex. Cercidium sp. (UCDC); Coahuila de Zaragoza: Torreon, 2q, 2 lâminas, 26.I.1956, P. DeBach col., ex. Persea americana (UCDC); Baja California Sur: La Paz, 12๕, 5 lâminas, VII.1919, G. F. Ferris col., ex. "ornamental" (UCDC); La Paz, calle Independencia y Revolucion, 89, 4 lâminas, 17.I.1962, F. Raney col., ex. Tamarix sp. (UCDC); San Lucas, 1919, 2q, 2 lâminas, G. F. Ferris col., Elaphrium microphyllum (UCDC); próximo San Lucas, ૬, VII.1919, G. F. Ferris col. (UCDC); San Jose del Cabo, 69, 3 lâminas, VII. 1919, G. F. Ferris col., ex. Musa sp. (UCDC); Todos Santos, 4q, 2 lâminas, VII.1919, G. F. Ferris col. (UCDC); idem, 3 \&, 2 lâminas, idem., ex. Persea americana (UCDC); idem, \&, idem., ex. Celosia sloribunda (UCDC); La Rivera, 1q, VII.1919, ex. Horchammeria watsoni (UCDC); Nayarit: 2q, 1 lâmina, sem data, sem coletor (UCDC 300); GUATEMALA, Solola: 2q, 1 lâmina, 24.VII.1960, S.W. Brown \& N. Rees col., ex. planta indeterminada (UCDC Mex III 31); HONDURAS, Zamorano, 2q, 1 lâmina, 15.I.1947, W. Popenoe col., ex. Camellia japonica (UCDC); PANAMÁ, Chiriqui: 2q, 1 lâmina, 1938, G. F. Ferris col. (UCDC 80); \&, 1938, G. F. Ferris col. (UCDC 88); 3q, 1 lâmina, sem data, sem coletor (UCDC 103); \&, 1938, G. F. Ferris col. (UCDC 130); 29, 2 lâminas, 1938, G. F. Ferris col. (UCDC 147); 2q, 2 lâminas, sem data, G. F. Ferris col., ex. Inga sp. (UCDC 162); §, 1938, sem coletor (UCDC 181); 2\&, 1 lâmina, 1938, sem coletor, ex. Inga sp. (UCDC 344); f, 1938, G. F. Ferris col. (UCDC 232); Boquete, 29, 1 lâmina, 1938, E. J. C. col., (UCDC 296); idem, 39, 1 lâmina, 1938, G. F. Ferris col. (UCDC 85); David, 2f, 1 lâmina, 1938, G. F. Ferris col. (UCDC 173); 3థ, 1 lâmina, sem data, E. J. C. col. (UCDC 352); Armuelles, 29, 1 lâmina, 1938, G. F. Ferris col., ex. Sapuim sp. (UCDC 71); idem, 5đ, 2 lâminas, 1938, G. F. Ferris col., ex. Inga sp. (UCDC 72); idem, \&, 1938, G. F. Ferris col. (UCDC 105); idem, 9£, 2 lâmina, 1938, G. F. Ferris col., ex. Inga sp. (UCDC 126); idem, 5\&, 2 lâminas, 1938, sem coletor, (UCDC 139); idem, 39, 1 lâmina, 1938, G. F. Ferris col. (UCDC 147); idem, 6‡, 2 lâminas, 1938, G. F. Ferris col. (UCDC 255); idem, 2q, 1 lâmina, 1938, G. F. Ferris col. (UCDC 262); idem, 2q, 1 lâmina, 1938, G. F. Ferris col. (UCDC 341); idem, 29, 1 lâmina, 1938, E. J. C. col., ex. planta indeterminada (UCDC 371); Pedregal, f, 1938, G. F. Ferris col. (UCDC 176); VENEZUELA, 5q, 1 lâmina, 10.XI.1937, R. N. Butthan col., ex. Cattleya mossiae (UCDC); BRASIL, Minas Gerais: Viçosa, 4q, 4 lâminas, 9.VII.1962, S. W. Brown col., ex. Magnolia sp. (UCDC); Rio de Janeiro: Nova Friburgo, escudos de $\widehat{\sigma}$ e $\subseteq$ em material herborizado, 1 tubo de vidro, IV.1898, E. Ule col. (MZSP 184); São Paulo: Campinas, \&, 16.XI.1934, H. Compere col., ex. Phoenix sp. (UCDC 69); Jardim Botânico, \&, XII.1958, J. P. da Fonseca col., ex. planta silvestre (MZSP 101); Jardim Botânico, 4q, 4 lâminas, 20.VII.1962, S. W. Brown col., ex. Myrciaria jaboticaba (UCDC); Praia Iporanga, 7£, 1 lâmina, 2.X.1959, J. P. da Fonseca col. (MZSP 49); São Paulo, Parque Siqueira Campos, 7\&, 1 lâmina, VII.1963, J. P. da Fonseca col., ex. Genipa sp. (MZSP 199); idem, 3q, 1 lâmina, III.1975, J. P. da Fonseca col., ex. Genipa sp. (MZSP 391); Santos, escudos de o e $q$ em material herborizado, 1 tubo de vidro, 23.VIII.1934, H. S. Lepage col. (IBSP 599). ARGENTINA, Formosa: P. N. Rio Pilcomayo, Estero Poí, 1千, 10.XII.1996, L. Claps, P. Zamudio col., ex. Tillandsiae sp (IMLA NEA71.96); Chaco: Avia Terai, Concepción del Bermejo, 9q, 2 lâminas, 18.II.1996, L. Claps, M. de Haro, P. Gonzalez, P. Zamudio col., ex. Prosopis huntzei (IMLA
C23.96); Catamarca: La Quebrada, La Cébila, 3‡, 04.XII.1994 L. Claps \& M. de Haro col. (IMLA C13.94); Tucumán: 7‡, 1 lâmina, 20.VIII.1940, Hayward col., ex. Mycearia edulis (CALT); Trancas, Ticucho, \&, 02.XI.1970, A. Terán col., ex. Jodina rhombifolia (IMLA 23); Ticucho, \&, 6.IV.1985, A. Terán col. (C 9.85); La Rioja: Patquia, Guayapa, 4£, IV.1943 Hayward col. (IMLA 3756).

Distribuição geográfica. Sri Lanka; Índia; Itália; Espanha; USA; México; Guatemala; Honduras; Panamá; Venezuela; Brasil; Argentina; Nova Zelândia.

Hospedeiros. Acanthaceae: Jacobina sp.; Amaranthaceae: Alternanthera bettzickiana Nichols., Celosia floribunda Gray; Anacardiaceae: Schinus sp., Schinus terebinthifolius Raddi; Anonaceae: Anona sp.; Apocynaceae: A. quebracho-blanco, Nerium sp., Nerium oleander L.; Aquifoliaceae: Ilex sp., Ilex vomitoria Ait.; Araliaceae: Hedera sp., Hedera helix L.; Aristochiaceae: Aristolochia sp., Asclemius sp.; Bignoniaceae: Bignonia sp., Kigelia pinnata DC., Pyrostegia sp., Pyrostegia ignea (Vell.); Bombacaceae: Ceiba sp.; Bromeliaceaea: Tillandsia sp.; Cactaceae: Rhipsalis sp.; Capparidaceae: Forchammeria watsoni; Caprifoliaceae: Lonicera sp., Viburnum tinus L., Viburnum odoratissimum Ker.; Caricaceae: Carica papaya L., Carica sp.; Caryophyllaceae: Dianthus sp., Dianthus caryophyllus L.; Celastraceae: Maytenus sp.; Cercidium sp.; Cercis canadensis L.; Ceroxylineae: Butia capitata (Mart.), Cocos nucifera L.; Chenopodiaceae: S. divaricata Moq.; Coryphineae: Chamaerops sp., Phoenix canariensis Chaub., Washingtonia sp.; Cycadaceae: Zamia integrifolia Ait.; Elaphrium microphyllum (A. Gray) Rose; Ericaceae: Gaylussacia sp., Vacciniumn sp.; Eryrthrina sp.; Euonymus sp.; Hamelia patens Jacq.; Howeia sp.; Euphorbiaceae: Acalypha sp., Sapium sp.; Lauraceae: Cinnamomum sp., Persea amearicana Mill., Persea borbonia (L.), Persea carolinensis Nees, Persea palustris (Raf.); Labiaceae: Coleus sp.; Leguminosae: Calliandra haematocephala Hassk., Cynometra sp., Cynometra oaxacuna, Prosopis huntzei; Inga sp.; Liliaceae: Smilax sp.; Yucca sp.; Magnoliaceae: Drimys sp., Magnolia sp., Magnolia grandiflora L., Magnolia obovata Thunb., Magnolia virginiana L.; Malvaceae: Hibiscus sp.; Melastomataceae: Tibouchina sp.; Moraceae: Ficus rubiginosa Vent.; Musaceae: Musa sp.; Myecaria edulis; Myrtaceae: Eugenia pungens Berg., M. jaboticaba Berg., Psidium sp., Psidium guajava L.; Oleaceae: Jasminum sp., Olea europea L., Osmanthus fragrans Lour; Orquidaceae: Cattleya sp., Cattleya mossiae Hooker; Cypripedium sp., Cyrtopodium punctatum (L.), Epidendrum tampense Ldl., Laelia sp., Oncidium varicosum Lindl, Vanda teres (Roxb.), Vanda hookeriana Rchb.; Phoenix sp.; Palmaceae: Chrysalidocarpus lutescens Wendl.; Polygalaceae: Polygala rugelii Schuttlw.; Prunoideae: Prunus sp.; Ptychosperma sp.; Rhacoma ilicifolia (Poir.); Roystonea sp; Rubiaceae: Genipa sp., Ixora sp.; Ruboideae: Rubus sp.; Santalaceae: Jodina rhombifolia Hook \& Arn.; Solanaceae: Cestrum diurnum L., C. nocturnum L.; Sterculiaceae: Theobroma cacao L.; Sabal sp.; Sabal palmetto (Walt.); Sapium sp.; Serenoa repens (Bart.); Tamarix sp.; Theaceae: Camellia japonica L.; Theophrastaceae: Jacquinia sp.; Trichostigma sp.; Thrinax sp. 
Discussão. Segundo FerRIS (1942), o comprimento da fêmea adulta é $0,75 \mathrm{~mm}$; nos exemplares examinados, o comprimento da fêmea adulta é em média $0,08 \mathrm{~mm}$ menor.

\section{Pseudoparlatoria perparvula Ferris, 1942}

Pseudoparlatoria perparvula FERRIS, 1942:SIV-418 (fig.); BorCHSENIUS, 1966:164 (cat); Miller, 1996:78.

Redescrição. Escudo do macho alongado, semelhante ao da fêmea quanto à textura e cor, exúvia apical (FERRIS, 1942). Escudo da fêmea oval-alongado, convexo, exúvias apicais (FERRIs, 1942).

Fêmea adulta oval, em média, 0,45 $\mathrm{mm}$ de comprimento e $0,35 \mathrm{~mm}$ de largura, tubérculo antenal com uma seta longa e uma curta, espiráculos anteriores e posteriores sem glândulas, lobos abdominais pré-pigidiais pouco desenvolvidos. Pigídio pequeno, curto, três pares de lóbulos: L1 largos, bem separados um do outro, com uma reentrância em cada lado, ápice pontiagudo; L2 pequenos, bilobados; L3 reduzidos. Margens antes de L3 levemente esclerotizadas. Um par de espinhos glandulares em forma de "y" entre L1; um espinho glandular longo, ápice simples entre L1 e L2; outro semelhante, entre L2 e L3, de cada lado das margens; antes de L3, espinhos glandulares curtos. Sem macrocondutos marginais entre os L1; um entre L1 e L2; dois entre L2 e L3; três antes de L3, mais afastados da margem. Dois macrocondutos submarginais, quase do mesmo tamanho dos marginais, de cada lado, próximos do ânus; demais menores, restritos ao pigídio. Abertura anal grande, a 0,02 $\mathrm{mm}$ da margem pigidial. Glândulas circungenitais em quatro ou cinco grupos: 0-2 medianos; 5-8 ântero-laterais; 6-7 pósterolaterais.

Material-tipo. Aqui designado: lectótipo §. MÉXICO, Colima: Manzanillo, 1925, G. F. Ferris col., ex. Hyperbaena denticulata (UCDC 808); paralectótipos: 5\%, 3 lâminas, mesmos dados do lectótipo (UCDC 808). Os síntipos do USNM e do VPIC não foram observados.

Distribuição geográfica. México.

Hospedeiro. Menispermaceae: Hyperbaena denticulata Standl.

\section{Pseudoparlatoria pisai (Hempel, 1904)}

Aspidiotus pisai Hempel, 1904:320, 1912:47; MacGillivray, 1921:400; Lepage, 1938:396 (cat.); Ferris, 1941a:47.

Pseudoparlatoria pizai; Lepage \& Giannotti, 1943:332-334 (fig.); Vernalha, 1953:194; Silva et al., 1968:180 (cat.).

Pseudoparlatoria pisai; Borchsenius, 1966:164 (cat.)

Redescrição. Macho desconhecido. Escudo da fêmea subcircular, 1 mm de diâmetro, convexo, marromescuro; exúvias apicais, amarelas.

Fêmea adulta oval, em média, $0,93 \mathrm{~mm}$ de comprimento e $0,75 \mathrm{~mm}$ de largura, tubérculos antenais com uma seta longa e duas curtas, espiráculos anteriores e posteriores sem glândulas, um lobo abdominal prépigidial de cada lado. Pigídio com três pares de lóbulos desenvolvidos: L1 arredondados, curtos e largos, bem separados um do outro; L2 e L3 bilobados. Um par de espinhos glandulares em forma de " $y$ " entre os L1; um espinho glandular, ápice simples e mais longo do que os lóbulos, entre L1 e L2 e entre L2 e L3, de cada lado; demais espinhos glandulares curtos. Margem anterior aos L3 esclerotizada e serreada, até o penúltimo segmento abdominal. Sem macrocondutos marginais entre os L1, dois entre L1 e L2, dois entre L2 e L3, de cada lado das margens. Macrocondutos submarginais menores que os marginais, em todo o pigídio, desde o III segmento abdominal. Ânus a $0,06 \mathrm{~mm}$ da margem pigidial. Glândulas circungenitais em cinco grupos: 2-3 medianos, 16-23 ântero-laterais, 19-27 póstero-laterais.

Material-tipo. Aqui designado: lectótipo . BRASIL, Rio de Janeiro: Itatiaia, 19.II.1904, A. Hempel col., ex. Drymis sp. (IBSP 81.10a); paralectótipos, 24\&, 13 escudos de \&, com mesmos dados do lectótipo; 4\%, 1 lâmina (IBSP); 20ㅇ, 4 lâminas (DZUP). Material examinado. BRASIL, Rio de Janeiro: Itatiaia, 2 escudos $\$$, 1 folha em tubo de vidro, 1912, A. Hempel col., ex. Drymis winterii (MZSP 237).

Distribuição geográfica. Brasil.

Hospedeiro. Winteraceae: Drymis sp.; Drymis winterii Forst.

Discussão. Segundo HemPEL (1904), o escudo mede 1,6 mm de comprimento e 1,1 mm de largura e a fêmea adulta $0,82 \mathrm{~mm}$ de comprimento. Os escudos examinados são $0,6 \mathrm{~mm}$ mais curtos, e a média do comprimento da fêmea é $0,11 \mathrm{~mm}$ maior.

LEPAGE \& GiannotTi (1943) transferem esta espécie para Pseudoparlatoria acrescentando a forma e distribuição dos espinhos glandulares, característica do gênero, além de considerá-la próxima a $P$. circularis, distinguindo-se desta pela forma e tamanho dos lóbulos pigidiais, pelo número de macrocondutos marginais e pela localização e distribuição das glândulas dorsais.

\section{Pseudoparlatoria punctata Ferris, 1942}

Pseudoparlatoria punctata FERRIS, 1942:SIV-420 (fig.); BORCHSENIUS, 1966:164 (cat.); Miller, 1996:78.

Redescrição. Escudo do macho alongado, semelhante ao da fêmea quanto à textura e cor; exúvia apical (Ferris, 1942). Escudo da fêmea circular, membranoso, branco ou cinza-claro; exúvia apical (FERRIS, 1942).

Fêmea adulta oval, em média, 0,69 $\mathrm{mm}$ de comprimento e $0,54 \mathrm{~mm}$ de largura, membranosa, exceto no pigídio, tubérculo antenal com uma seta longa, espiráculos anteriores e posteriores sem glândulas, sem lobos abdominais pré-pigidiais. Glândulas curtas na margem do cefalotórax, até o III ou IV segmentos abdominais. Pigídio com três pares de lóbulos desenvolvidos: L1 grandes, separados um do outro, com uma reentrância de cada lado, ápice arredondado; L2 bilobados; L3 pouco desenvolvidos. Um par de espinhos glandulares longos, em forma de "y", entre os L1, um espinho glandular longo, com ápice simples, entre L1-L2, outro semelhante, entre L2-L3, de cada lado das margens; antes de L3, espinhos glandulares inconspícuos. Sem macrocondutos marginais entre os L1, um entre L1-L2, dois entre L2-L3 e três antes de L3, de cada lado das margens. Um macroconduto submarginal, no VII segmento 
abdominal, com tamanho semelhante aos marginais, de cada lado; demais macrocondutos submarginais menores, até os primeiros segmentos abdominais. Ânus a $0,03 \mathrm{~mm}$ da margem do pigídio. Glândulas circungenitais em quatro ou cinco grupos: 0-1 medianos, 10-17 ântero-laterais, póstero-laterais.

Material-tipo. Aqui designado: lectótipo ‡. MÉXICO, Guerrero: 30 km leste de Acapulco, 1926, G. F. Ferris col., ex. Mimosaceae (UCDC 458); paralectotipos: 3‡, 2 lâminas, mesmos dados do lectótipo. Síntipo do USNM não observado.

Distribuição geográfica. México.

Hospedeiro. Mimosaceae.

Discussão. Semelhante a $P$. rossettae por apresentar glândulas curtas na margem do cefalotórax; diferenciase pela maior quantidade de glândulas submarginais.

\section{Pseudoparlatoria rossettae Fonseca, 1969}

Pseudoparlatoria rossettae FonsecA, 1969:20-22 (fig.).

Redescrição. Macho desconhecido. Escudo da fêmea subcircular, 1,2 mm de diâmetro, membranoso, semitransparente, exúvias apicais amarelas.

Fêmea adulta oval, em média, $0,64 \mathrm{~mm}$ de comprimento e $0,54 \mathrm{~mm}$ de largura. Tubérculo antenal com duas setas longas, espiráculos anteriores e posteriores sem glândulas, sem lobos abdominais prépigidiais. Pigídio com três pares de lóbulos: L1 tão largos quanto longos, bem separados um do outro, com uma reentrância em cada lado; L2 diminutos, levemente bilobados, ápice arredondado; L3 inconspícuos. Um par de espinhos glandulares longos, em forma de "y", entre os L1, um espinho glandular longo e com ápice simples entre L1 e L2, outro semelhante entre L2 e L3, de cada lado das margens; antes de L3, espinhos glandulares curtos. Sem macrocondutos marginais entre os L1, um entre L1 e L2, dois entre L2 e L3, três antes de L3, de cada lado das margens. Margem anterior a L3 serrilhada e esclerotizada. Um macroconduto submarginal, de cada lado, próximo ao ânus, quase do mesmo tamanho dos marginais, os demais um pouco menores, restritos ao pigídio. Uma série de glândulas dorsais curtas na margem do cefalotórax e nos primeiros segmentos abdominais. Ânus a $0,03 \mathrm{~mm}$ da margem pigidial. Glândulas circungenitais em quatro grupos: 11-20 ântero-laterais, 8-18 póstero-laterais.

Material-tipo. Aqui designado: lectótipo. BRASIL, São Paulo: [São Paulo,] Parque Siqueira Campos, VII.1967, J. P. Fonseca col., ex. Cassaria sylvestris (MZSP 857); Paralectótipos: 26Ғ, 2 lâminas, mesmos dados do lectótipo (IBSP) (1 ret. MRGC 341); 15๕, 6 lâminas, (MZSP); escudos de $\varsubsetneqq$ em material herborizado, 1 tubo de vidro (IBSP 857); escudos de $\subsetneq$ em material herborizado, 1 tubo de vidro (MZSP 857). Uma lâmina do IBSP, com etiquetas indicando "Pseudoparlatoria rossettae Fonseca, Cotypus 857" não apresenta esta espécie e sim espécimes de Diaspidistis squamosa Hempel, 1937.

Material examinado. BRASIL, São Paulo: São Paulo, Parque Siqueira Campos, 40‡, 8 lâminas, IX.1958, J. P. Fonseca col., ex. Cassaria sylvestris (MZSP 66); idem, 9q, 3 lâminas, 19.X.1959, mesmo coletor (MZSP 121); idem, 18̊, 1 lâmina, XII.1959, mesmo coletor, planta silvestre (MZSP 129); idem, 15ף, 1 lâmina, mesma data, mesmo coletor., ex. Cassaria sylvestris (MZSP 130); idem, 42£, 3 lâminas, VII.1963, mesmo coletor, ex.
Genipa sp. (MZSP 198); idem, 3f, 1 lâmina, VI.1968, mesmo coletor, ex. Cassaria sylvestris (MZSP 265); idem, 7‡, 1 lâmina, XI.1968, mesmo coletor, ex. Myrtaceae (MZSP 379); idem, 219, 1 lâmina, sem data, mesmo coletor., ex. planta silvestre (MZSP 390); idem, 12q, 1 lâmina, IX.1977, sem coletor (MZSP 453); idem, 25๕, 1 lâmina, V.1977, J. P. Fonseca col., ex. Cassaria sylvestris (MZSP 461); idem, 17@, 1 lâmina, X.1978, sem coletor (MZSP 492), Morumbi, 149, 2 lâminas, V.1967, J .P. Fonseca col., planta silvestre (MZSP 266); Jardim da Luz, F, XII.1976, sem coletor, ex. Myrcia jaboticaba (MZSP 444); Serra da Cantareira, 24\&, 2 lâminas, IX.1958, J. P. Fonseca col., ex. Myrtaceae (MZSP 94); idem, 4Y, 1 lâmina, XII.1958, mesmo coletor, ex. planta silvestre (MZSP 96); idem, 17‡, 3 lâminas, V.1963, mesmo coletor, ex. Cassaria sylvestris (MZSP 194).

Distribuição geográfica. Brasil.

Hospedeiro. Flacourtiaceae: Cassaria sylvestris Su.; Myrtaceae: M. jaboticaba; Rubiaceae: Genipa sp.; planta silvestre.

Discussão: Segundo LePage \& GiannotTi (1943), as medidas dos escudos são de 1,6 mm de comprimento, $1,1 \mathrm{~mm}$ de largura e o comprimento do corpo da fêmea $0,82 \mathrm{~mm}$. No material examinado, a média do comprimento dos escudos é $0,4 \mathrm{~mm}$ menor e do comprimento da fêmea $0,18 \mathrm{~mm}$ menor.

\section{Pseudoparlatoria sculpta (Ferris, 1941) comb. nov.}

Malleolaspis sculpta FERRIS, 1941b:SIII-292 (fig.); BorCHSENIUS, 1966:162 (cat.).

Redescrição. Escudo do macho não encontrado (FERRIS, 1941b). Escudo da fêmea adulta circular, membranoso, achatado, amarelo, com exúvia excêntrica (FERRIS, 1941b).

Fêmea adulta com o corpo esclerotinizado, cefalotórax semicircular, muito alargado, constrição no metatórax, em média, 1,02 mm de comprimento e 0,73 mm de largura, três lobos abdominais pré-pigidiais, tubérculo antenal com três setas, espiráculos anteriores e posteriores sem glândulas. Pigídio com três pares de lóbulos: L1 largos, margens com uma reentrância de cada lado, ápice arredondado; L2 bilobados e L3 reduzidos. Margem anterior aos L3 esclerotizada. Um par de espinhos glandulares em forma de "y" entre os L1; um espinho glandular com ponta simples entre L1-L2; outro semelhante, mais longo do que os lóbulos, em ambas as margens, entre L2-L3; espinhos glandulares reduzidos antes de L3. Um macroconduto marginal entre os L1, um entre L1-L2, dois entre L2-L3, três antes de L3. Macroconduto submarginal, no VII segmento, quase do mesmo tamanho dos marginais; demais menores, em grande quantidade, até os primeiros segmentos abdominais. Ânus a $0,06 \mathrm{~mm}$ da margem pigidial. Glândulas circungenitais em quatro grupos: 17-20 ânterolaterais, 10-14 póstero-laterais. Microcondutos presentes nos lobos abdominais pré-pigidiais e no pigídio.

Material-tipo. Aqui designado: lectótipo §. PANAMÁ, Chiriqui: Volcan de Chiriqui, 1938, Ferris, ex. planta indeterminada (USNM 207); paralectótipo: $\subsetneq$, mesmos dados do lectótipo (USNM 551). Síntipos do UCDC e VPIC não examinados.

Material examinado. PANAMÁ, Chiriqui: Volcan de Chiriqui, \&, 1938, Ferris col., ex. planta indeterminada (USNM 181); Armuelles, 4q, 1 lâmina, 1938, Ferris col., ex. Leguminosae (UCDC 309). 
Distribuição geográfica. Panamá.

Hospedeiros. Leguminosae; planta indeterminada.

Discussão. Esta espécie é semelhante a $P$. fusiformis e a $P$. mammata pela forma do cefalotórax e constrição no metatórax. Diferencia-se de P. fusiformis pela presença de um macroconduto marginal entre os lóbulos medianos e de P. mammata pela ausência de lobos pontiagudos no metatórax e primeiro segmento abdominal.

\section{Pseudoparlatoria serrulata Townsend \& Cockerell, 1898}

Pseudoparlatoria serrulata Townsend \& CoCKerell, 1898:180; MacGillivray, 1921:314; Ferris, 1942:SIV-421 (fig.); Borchsenius, 1966:165 (cat.); Miller, 1996:78.

Redescrição. Escudo do macho oval, $1 \mathrm{~mm}$ de diâmetro, achatado, textura e cor semelhantes ao da fêmea, exúvia terminal (FERRIs, 1942). Escudo da fêmea subcircular, $1,5 \mathrm{~mm}$ a $2 \mathrm{~mm}$, levemente convexo, membranoso, branco ou cinza, canelado; exúvia submarginal (FERRIS, 1942).

Fêmea adulta oval, em média, $0,81 \mathrm{~mm}$ de comprimento, 0,68 $\mathrm{mm}$ de largura, tubérculo antenal com uma seta longa e duas curtas, espiráculos anteriores e posteriores sem glândulas, sem lobos abdominais prépigidiais. Pigídio com três pares de lóbulos: L1 com ápice arredondado e com uma reentrância em cada lado, bem separados um do outro; L2 reduzidos, bilobados; L3 com pequena ponta, não esclerotinizado. Um par de espinhos glandulares em forma de " $y$ " entre os L1; um espinho glandular, mais longo do que os lóbulos e com ápice simples entre L1 e L2; outro semelhante antes de L2, de cada lado; os demais espinhos muito curtos. Sem macrocondutos marginais entre os L1, um entre L1 e L2, dois antes de L2 e três antes de L3, de cada lado das margens. Um macroconduto submarginal, de cada lado, no VII segmento, quase do mesmo tamanho dos marginais; os demais menores, do VI até os primeiros segmentos abdominais. Ânus a $0,03 \mathrm{~mm}$ da margem pigidial. Glândulas circungenitais em quatro ou cinco grupos: 0-4 mediano, 9-21 ântero-laterais, 11-15 póstero-laterais.

Material-tipo. Aqui designado: lectótipo \&. MEXICO, Sonora: Hermosillo, 23.IV.1897, A. Koebele col., ex. planta indeterminada (USNM 1719); paralectótipos: 16‡, 4 lâminas, mesmos dados do lectótipo, (USNM).

Material examinado: MÉXICO, Sonora: Hermosillo, 10क, 4 lâminas, sem data, Koebele col. (UCDC); 2q, 1 lâmina, 17.VII.1912, Quer. S, F. col., ex. "guara" (UCDC); Guara, 4\&, 1 lâmina, sem data, E. J. C. col. (UCDC George Compere Collection 1352); Imuris, 3‡, 2 lâminas, III.1934, G. F. Ferris col., ex. Celtis pallida (UCDC); Durango: San Juan de Rio, 2q, 2 lâminas, 28.III.1956, P. de Bach col., ex. "Indian laurel" (UCDC S 32); Colima, 2‡, 1 lâmina, sem data, G. F. Ferris col., ex. Dalea sp. (UCDC 176); 2\&, 2 lâminas, sem data, G. F. Ferris col., ex. Orquidaceae (UCDC 841); Guerrero: próximo a Acapulco, 2\&, 1 lâmina, km 30, sem data, sem coletor, ex. Vitis sp. (UCDC 235). REPÚBLICA DOMINICANA, La Vega: Constanza, q, 01.IX.1969, F. G. Hawksworth \& L. D. Wiens col., ex. Arcenthobium bicarinatum (VPIC). BRASIL, São Paulo: Serra da Cantareira, 22q, 2 lâminas, VIII.1958, J. P. da Fonseca col., ex. Merostachys sp. (MZSP 62). ARGENTINA, Formosa: Pilcomayo, P. N. Rio Pilcomayo-Estero Poi (Sendero), 4\%, 1 lâmina, 10.XII.1996, L. Claps \& P. Zamudio col. (IMLA NEA 12.96); Catamarca: San Fernando, Belén, Santa Maria, 4\&, 1 lâmina, 20.XII.1986, L. Claps col., ex. Sueda divaricata (IMLA C 56.86);
San Martin, Chumbicha, 4\&, 1 lâmina, 04.XII.1994, L. Claps, M. de Haro col., ex. Sueda divaricata (IMLA C56.91); Santiago del Estero: El 49, 39, 1 lâmina, 01.XII.1994, L. Claps \& M. de Haro col., ex. Larrea divaricata (IMLA C29.94); La Rioja: Schaqui, 29 , 1 lâmina, 21.IX.1991, L. Claps, M. de Haro \& M. I. Zamar col. (IMLA C39.91).

Distribuição geográfica. México, República Dominicana, Brasil, Argentina.

Hospedeiro. Viscaceae: Arcenthobium bicarinatum Urban; Capparidaceae: Frochammeria watsoni; Chenopodiaceae: S. divaricata Moq.; Dalea sp.; Leguminosae: Cercidium sp.; Merostachys sp.; Myrtaceae: Myrtus sp.; Orchidaceae; Palmaceae: Thithrinax campestris (Burm.); Theophrastaceae: Jacquinia sp.; Ulmaceae: Celtis pallida Torr.; Vitaceae: Vitis sp.; Zygophyllaceae: Larrea divaricata Cav.

\section{Pseudoparlatoria subcircularis Balachowsky, 1959}

Pseudoparlatoria subcircularis Balachowsky, 1959:352-353 (fig.); BORCHSENIUS, 1966:165 (cat.).

Redescrição. Macho desconhecido. Escudo da fêmea oval, de 1-1,3 mm de diâmetro, cinza, formado por camadas concêntricas de pouco relevo; exúvia excêntrica amarelo-dourada, com uma carena central (BALACHOWSKY, 1959).

Fêmea adulta subcircular, em média, $0,59 \mathrm{~mm}$ de comprimento e $0,56 \mathrm{~mm}$ de largura, membranosa, espiráculos anteriores e posteriores sem glândulas, tubérculo antenal com uma seta longa, sem lobos abdominais pré-pigidiais. Pigídio largo, quase horizontal, com três pares de lóbulos: L1 pequenos, margem arredondada, bem afastados um do outro; L2 pequenos, bilobados; L3 com pequena ponta esclerotizada. Margens dos segmentos VI e V denticuladas e esclerotizadas. Um par de espinhos glandulares em forma de "y" entre os L1; um espinho glandular longo, com pontas simples, entre L1 e L2; outro semelhante entre L2 e L3, de cada lado; inconspícuos antes de L3. Um macroconduto marginal entre os L1; um entre L1 e L2 e quatro antes de L2, de cada lado das margens. No VII segmento, um macroconduto submarginal quase do mesmo tamanho dos marginais, de cada lado; entre os segmentos V e VI, três ou quatro macrocondutos submarginais um pouco menores. Ânus a $0,02 \mathrm{~mm}$ da margem pigidial. Glândulas circungenitais em cinco grupos: 1-4 mediano, 6-10 ânterolaterais, 6-9 póstero-laterais.

Material-tipo. Aqui designado: lectótipo §. COLÔMBIA, Cauca: Vale de Cali, 17.I.1957, A. Balachowsky col., ex. Calocarpum sp. (MNHN 2567); paralectótipos: 7\&, 5 lâminas, mesmos dados do lectótipo (MNHN 2567)

Distribuição geográfica. Colômbia.

Hospedeiro. Sapotaceae. Calocarpum sp.

Pseudoparlatoria tillandsiae Tippins, 1970

Pseudoparlatoria tillandsiae TiPPINs, 1970:818-819 (fig.).

Redescrição. Escudo da fêmea alongado, 1,5 mm de comprimento e $0,5 \mathrm{~mm}$ de largura, marrom-arroxeado claro a esbranquiçado (Tippins, 1970).

Fêmea adulta oval alongada, em média, $0,76 \mathrm{~mm}$ de 
comprimento e $0,35 \mathrm{~mm}$ de largura, tubérculo antenal com uma seta longa e duas curtas, espiráculos anteriores e posteriores sem glândulas, lobos abdominais prépigidiais levemente desenvolvidos. Pigídio com três pares de lóbulos: L1 longos, pontiagudos, com uma reentrância na margem interna e quatro na margem externa; L2 bem desenvolvidos, bilobados; L3 inconspícuos. Um par de espinhos glandulares em forma de "y", mais curtos do que os lóbulos, entre os L1; um espinho glandular, com ápices simples, entre L1 e L2; outro semelhante antes de L2, de cada lado das margens; demais espinhos glandulares inconspícuos. Margem anterior aos lóbulos lisa. Sem macrocondutos marginais entre os L1; um entre L1 e L2; dois entre L2 e L3, três antes de L3, de cada lado das margens. Cinco a sete macrocondutos submarginais, quase do mesmo tamanho que os marginais, até o IV segmento abdominal. Ânus a $0,06 \mathrm{~mm}$ da margem do pigídio. Glândulas circungenitais em quatro, raramente cinco grupos: 0-1 mediano, 3-7 ântero-laterais, 6-11 póstero-laterais.

Material-tipo. Holótipo §. EUA, Georgia: Echols County, 4.V.1968, Beshear col., ex. Tillandsia usneoides (UGCA); parátipos: 3‡, mesmos dados do holótipo (USNM), não examinados.

Material examinado: EUA, Georgia: Echols County, $q$, 7.II.1970, R. Beshear col., ex. Tillandsia sp. (VPIC). O exemplar observado é proveniente da mesma localidade-tipo.

Distribuição geográfica. EUA.

Hospedeiro. Bromeliaceae: Tillandsia usneoides L., Tillandsia sp.

Discussão. Segundo TiPPINS (1970), esta espécie é semelhante a $P$. elongata, mas difere pela forma dos lóbulos medianos, tamanho da abertura anal, número de macrocondutos marginais no segundo espaço interlobular e presença de um espinho ocular.

\section{Pseudoparlatoria trimaculata Lepage \& Giannotti, 1946}

Pseudoparlatoria trimaculata LePAGE \& GiannotTi, 1946:37-40 (fig.); Vernalha, 1953: 194; Borchsenius, 1966:165 (cat.).

Redescrição. Escudo do macho alongado, em média, 1,32 $\mathrm{mm}$ de comprimento e 0,91 $\mathrm{mm}$ de largura, membranoso, amarelo a marrom-escuro; exúvia apical, amarela, sem mancha. Escudo da fêmea subcircular, em média, $1,81 \mathrm{~mm}$ de comprimento e 1,56 $\mathrm{mm}$ de largura, amarelo a marrom; exúvias apicais, amarelas, com três manchas na segunda exúvia, uma anterior mediana e duas laterais na parte posterior.

Fêmea adulta oval, em média, $0,77 \mathrm{~mm}$ de comprimento e $0,64 \mathrm{~mm}$ de largura, membranosa, tubérculo antenal com uma seta longa, espiráculos anteriores e posteriores sem glândulas, três lobos abdominais prépigidiais desenvolvidos. Pigídio com três pares de lóbulos: L1 pequenos, arredondados, bem separados um do outro; L2 pequenos, arredondados, bilobados; L3 inconspícuos. Espinhos glandulares mais longos que os lóbulos; um par, em forma de "y", entre os L1; um espinho com ápice simples entre L1 e L2; outro semelhante antes de L2, de cada lado das margens; demais espinhos glandulares curtos. Margem anterior aos lóbulos esclerotizada e com fino serrilhado. Um macroconduto marginal entre os L1; um entre L1 e L2; dois entre L2 e L3, dois antes de L3, de cada lado das margens. Um macroconduto submarginal, quase do mesmo tamanho dos marginais, no VII segmento abdominal; várias séries de macrocondutos, um pouco menores, até os primeiros segmentos abdominais. Ânus a $0,04 \mathrm{~mm}$ da margem pigidial. Glândulas circungenitais em cinco grupos: 2-7 mediano, 13-25 ântero-laterais, 10-25 póstero-laterais.

Material-tipo. Aqui designado: lectótipo §. BRASIL, São Paulo: Campos do Jordão, V.1945, F. P. Mello col., ex. planta indeterminada (IBSP); paralectótipo: †, na mesma lâmina do lectótipo; escudos de o e 9 em 4 folhas, um tubo de vidro (IBSP). Material examinado: BRASIL, São Paulo: Campos do Jordão, 12\&, 4 lâminas, V.1945, F. P. Mello col., (MZSP); escudos de $\sigma^{7}$ e $\subsetneq$ em uma folha, um tubo de vidro (MZSP 737).

Distribuição geográfica. Brasil.

Discussão. Segundo Lepage \& Giannotti (1946), $P$. trimaculata é semelhante a $P$. maculata, distinguindose por apresentar no escudo da fêmea adulta três zonas pigmentadas, ao passo que em $P$. maculata há apenas uma; a fêmea adulta de $P$. maculata mede cerca de $1 \mathrm{~mm}$ de comprimento. As fêmeas adultas examinadas são menores e distinguem-se das de $P$. maculata pela maior quantidade de macrocondutos submarginais.

\section{Pseudoparlatoria turgida Ferris, 1941}

Pseudoparlatoria turgida FerRIs, 1941b:SIII-319 (fig.); BorChSENIUS, 1966:165 (cat.).

Redescrição. Macho desconhecido. Escudo da fêmea subcircular, membranoso, transparente, amareloclaro, com exúvias submarginais (FerRIS, 1941b).

Fêmea adulta com derme esclerotizada, forma oval alongada, afilada na região posterior, em média, 1,02 mm de comprimento e $0,64 \mathrm{~mm}$ de largura, tubérculo antenal com uma seta longa e três curtas, estigma anterior sem glândulas, sem lobos abdominais pré-pigidiais. Pigídio com três pares de lóbulos: L1 largos, bem separados um do outro, uma reentrância de cada lado e ápice arredondado; L2 muito pequenos, bilobados; L3 inconspícuos. Um par de espinhos glandulares mais longos do que os lóbulos, em forma de "y", entre os L1; um espinho glandular, com pontas simples e longas, entre L1 e L2; outro semelhante antes de L2, de cada lado das margens; demais espinhos glandulares muito curtos. Não há macrocondutos marginais entre os L1; um entre L1 e L2; dois entre L2 e L3; três antes de L3. Um par de macrocondutos submarginais, aproximadamente do tamanho dos marginais, no VI segmento; demais menores, restritos ao pigídio. Ânus a $0,03 \mathrm{~mm}$ da margem pigidial. Glândulas circungenitais em quatro grupos: 0-3 medianos, 8-14 ântero-laterais, 7-13 póstero-laterais.

Material-tipo. Holótipo \&. PANAMÁ, Chiriqui: Armuelles, 1938, G. F. Ferris col., ex. Eugenia sp.; parátipos mesma localidadetipo, ex. Pyrenoglyphus sp.

A busca pelo material-tipo foi realizada no UCDC, USNM e VPIC, não sendo localizado. O material examinado do UCDC, proveniente do Panamá, é da mesma localidade-tipo e foi determinado por Ferris. 
Material examinado. MÉXICO, Jalisco: Puerto Vallarta, 2q, 1 lâmina, 26.XII.1957, S. W. Brocon col., ex. "cola-de-iguana" (UCDC); PANAMÁ, Chiriqui: Armuelles, 29, 1 lâmina, 1938, ex. Pyrenoglyphus sp. (UCDC 44); idem, 4థ, 2 lâminas, mesma data (UCDC 240); idem, 5§, 2 lâminas, mesma data (UCDC 256); 4ף, 2 lâminas, mesma data (UCDC 257); ARGENTINA, Chaco: Laguna Carpincho, 2f, 1 lâmina, 1.XI.1996, L. Claps, P. González \& P. Zamudio col., ex. Trithrinax campestris (IMLA NEA6.96).

Distribuição geográfica. México, Panamá, Argentina.

Hospedeiro. Myrtaceae: Eugenia sp.; Palmaceae: Pyrenoglyphus sp.; T. campestris (Burm.); "cola-deiguana"; planta indeterminada.

Discussão. Segundo FERRIS (1941b), a fêmea adulta de $P$. turgida é semelhante a $P$. elongata quanto à forma do corpo; difere desta e das demais espécies deste gênero, por apresentar o corpo muito esclerotinizado quando madura e poucas glândulas dorsais, confinadas ao pigídio.

Agradecimentos. Ao Prof. Dr. Gervásio Silva Carvalho (PUCRS), pela orientação, amizade e incentivo ao trabalho. Á Prof $^{a}{ }^{\text {Dr }}{ }^{\mathrm{a}}$ Lucía Elena Claps (IMLA), pela grande colaboração que ofereceu ao trabalho pela sua experiência com os diaspidídeos. Aos curadores e responsáveis pelas coleções: Dr. P. A. Brown (BMNH); Biól. J. Justi Junior e Dr. S. Ide (IBSP); Dra. L. E. Claps (IMLA); Dra. D. Matile-Ferrero (MNHN); Eng. Agr. W. Caetano (MRGC); Biól. C. Camponer (MZSP); Dr. D. R. Miller (USNM); Dr. M Kosztarab (VPIC); Dr. H. Struempel (ZMUH); pelo empréstimo de material. À CAPES pela bolsa de doutorado.

\section{REFERÊNCIAS BIBLIOGRÁFICAS}

Balachowsky, A. S. 1954. Les cochenilles Paléarctiques de la tribu des Diaspidini. (In French), Paris, Memmoires Scientifiques de 1'Institut Pasteur. 450p

1959. Nuevas cochinillas de Colombia. Revista de la Academia Colombiana de Ciencias Exactas, Físicas y Naturales 10(41):337-361.

Borchsenius, N. S. 1966. A catalogue of the armored scale insects (Diaspidoidea) of the World. Moscou, Zoologicheskii Institut. 449p.

Claps, L. E. \& Gonzales, P. 1995. Conociendo nuestra fauna V. Familia Diaspididae (Insecta: Homoptera). Clave de generos del NOA y lista actualizada de hospedeiros. Serie Monografica y Didactica. San Miguel de Tucuman. Facultad de Ciencias Naturales y Instituto Miguel Lillo UNT 23:1-35

Cockerell, T. D. A. 1892. Museum notes. Journal of the Institute of Jamaica 1:134-137.

Cockerell, T. D. A. 1897. Further notes on Coccidae from Brazil. Revista do Museu Paulista 2:383-384.

1898a. Three new Coccidae of the subfamily Diaspinae. Psyche 8:201-203.

1898b. Some new Coccidae. Revista do Museu Paulista 3:41-44

1898c. Mais algumas Coccidae. Revista do Museu Paulista 3:501-503

Сомsтоск, J. H. 1883. Second report on scale insects, including a monograpf of the subfamily Diaspidinae of the family Coccidae and a list, with notes, of the species of scale insects found in North America. Cornell University Agricultural Experiment Station. Department Entomology 2:47-142.

Corseuil, E. \& Silva, T. L. 1971. A tribo Diaspidini no Rio Grande do Sul (Hom., Diaspididae). Arquivos do Museu Nacional do Rio de Janeiro 54:109-112.

Costa, R. G. \& Redaelli, D. C. 1949. Cochonilhas ou coccídeas do Rio Grande do Sul. Porto Alegre, Secção de Informações e Publicidade Agrícola. 107p.

Costa Lima, A. M. DA. 1936. Terceiro catálogo dos insetos que vivem nas plantas do Brasil. Rio de Janeiro, Ministério da
Agricultura, Escola Nacional. Escola Nacional de Agronomia. $460 p$.

Fernald, M. E. 1903. A catalogue of the Coccidae of the World Agricultural Experiment Station Special Bulletin 88:1360

Ferris, G. F. 1937. Atlas of the scale insects of North America. Palo Alto, Stanford University. 136p.

1941a. Contributions to the knowledge of the Coccoidea (Homoptera). Microentomology 6:33-70.

1941b. Atlas of the scale insects of North America Series III. Palo Alto, Stanford University. $115 p$. 1942. Atlas of the scale insects of North America. Series IV. Palo Alto, Stanford University. 253p.

FonseCA, J. P. DA. 1969. Contribuição ao conhecimento dos coccideos do Brasil (Homoptera-Coccoidea). Arquivos do Instituto Biológico 36(1):9-40.

1975. Três novas espécies de coccídeos do Brasil (HomopteraCoccoidea). Arquivos do Instituto Biológico 42:79-84

Green, E. E. 1922. Suplementary notes on the Coccidae of Ceylon. Parte IV. Journal of the Bombay Natural History Society 28:1007-1037.

Hempel, A. 1900. As coccidas brasileiras. Revista do Museu Paulista 4:365-537. 1904. Exame de diversas collecções da Coccidas. Boletim Agricultura 5(7):311- 323

1912. Catálogos da Fauna Brazileira. As Coccidas do Brasil. São Paulo, Museu Paulista. v. 3, 77p.

1937. Novas espécies de coccídeos (Homoptera) do Brasil. Arquivos do Instituto Biológico 8:25-36.

LeOnARDI, G. 1914. Contributo alla conoscenza delle coccinglie dell'Africa occidentale e meridionale. Bollettino del Laboratorio di Zoologia Generale e Agraria della Scuola Superior Agricoltura 8:187-224.

Lepage, H. S. 1938. Catálogo dos coccideos do Brasil. Revista do Museu Paulista 23:390-421

1942. Descrição de onze espécies novas de coccídeos do Brasil (Homoptera-Coccoidea). Arquivos do Instituto Biológico 13:173-189.

Lepage, H. S. \& Giannotti, O. 1943. Notas coccidológicas (Homoptera- Coccoidea). Arquivos Instituto Biológico 14:332-350.

1946. Contribuição para o conhecimento dos coccídeos do Brasil (Homoptera - Coccoidea). Arquivos do Instituto Biológico 17:37-46.

LiNDINGER, L. 1909. Beiträge zur Kenntnis der Schikdläuse und ihner Verbreitung. Zeitschrift für Wissenschaftliche Insektsmbiologie 5:105-110.

1911. Beiträge zur Kenntnis der Schikdläuse und ihner Verbreitung II. Zeitschrift für Wissenschaftliche Insektsmbiolgie 7:9-10.

1912. Die Schikdläuse (Coccidae) Europas. Nordafrikas und Vorder-Asiens, einschliesslich der Azoren, der Kanaren und Madeiras. Stuttgart, Ulmer. $388 \mathrm{p}$.

LindingER, L. 1928. Bericht über die Tätigkeit der Abteilung für Pflanzenschutz. A. Überwachung der Ein- und Ausfuhr von Obst und Pflanzen (amtliche Pflanzenbeschau.). Hamburgerischen Institut für Angewandte Botanie. Jahresberichte. $110 \mathrm{p}$.

Lizer y Trelles, C. A. 1942. Cochinillas halladas por primera vez en la Argentina (Hom. Sternor.). Revista de la Sociedad Entomologica Argentina 11(2):230-236.

MacGillivray, A. D. 1921. The Coccidae. Scarab, Urbana 502p. MAMET, R. 1953. Notes of the Coccoidea of Madagascar III Memoires de L'Institut Scientifique de Madagascar 4:1-86.

McKenzie, H. L. 1956. The armored scale insects of California Bulletin of the California Insect Survey 5:1-209.

1963. Miscellaneouns diaspidid scale studies, including a new asterolecaniid from Florida (Homoptera; Coccoidea; Diaspididae; Asterolecaniidae). Scale studies. Part XV Bulletin of the Department of Agriculture 52:29-39.

Miller, D. R. 1996. Checklist of the scale insects (Coccoidea: Homoptera) of Mexico. Proceedings of the Entomological Society of Washington 98:68-86. 
Tippins, H. H. 1970. A new species of Pseudoparlatoria (Homoptera: Diaspididae) from Georgia. Annals of the Entomological Society of America 63(3):818-819.

Townsend, H. \& Cockerell, T. D. A. 1898. Coccidae collected in Mexico by Messrs. Journal of the New York Entomological Society 6:165-181.

Silva, A. G. D. A., Gonçalves, C. R.; Galvão, D. M.; Gonçalves, A. J. L., J.; Gomes, J.; Silva, M. do N. \& Simoni, L. DE. 1968. Quarto catálogo dos insetos que vivem nas plantas do Brasil, seus parasitos e predadores. Parte II, $1^{\circ}$ tomo.
Insetos, hospedeiros e inimigos naturais. Rio de Janeiro, Ministério da Agricultura. 622p.

Vernalha, M. M. 1953. Coccídeos da coleção I.B.P.T. Arquivos de Biologia e Tecnologia 8(12):162-197.

1957. Contribuição para o conhecimento dos coccídeos (Homoptera, Coccoidea) de Ilex sp. no Estado do Paraná. Curitiba, Escola Superior de Agronomia e Veterinária do Paraná. 52p.

Wolff, V. R. S. 2001. Dez espécies novas de Pseudoparlatoria Cockerell, 1892 (Hemiptera; Coccoidea; Diaspididae). Arquivos do Instituto Biológico 68(2):67-76. 